ESPECIAL

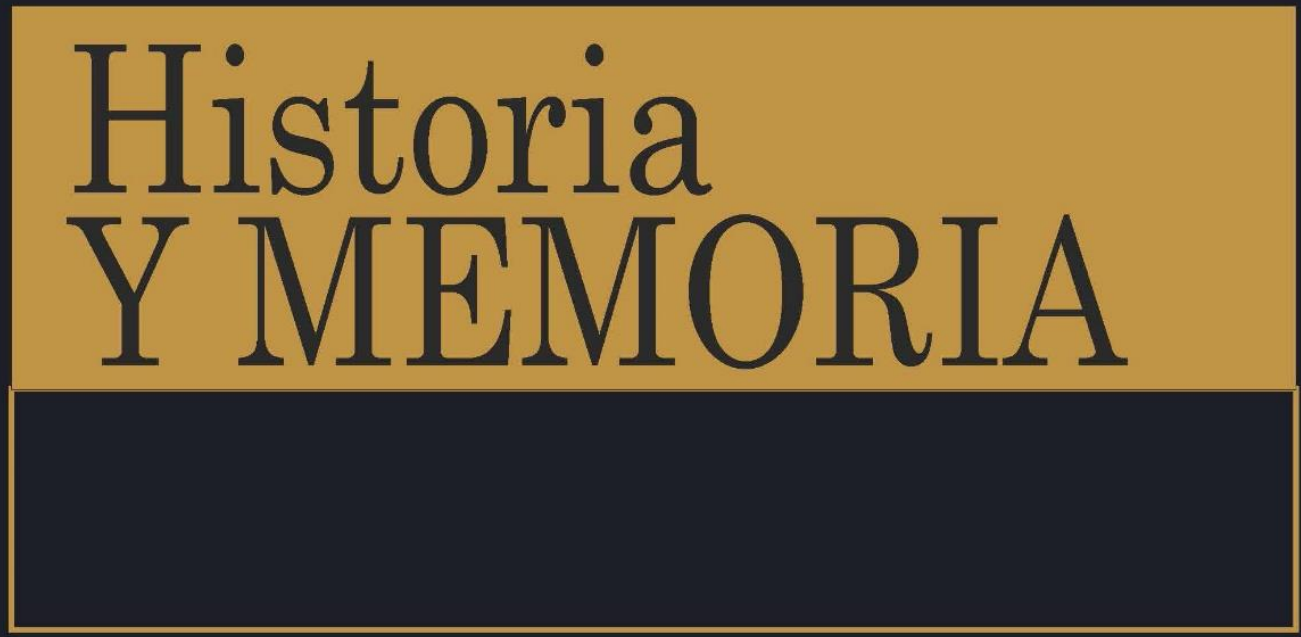

ISSN: 2027-5137 Número Especial • 10 Años • Año 2020 - Tunja, Colombia

¿Qué hay de histórico en la Historiografía ambiental en América Latina?

https://doi.org/10.19053/20275137.nespecial.2020.11586

Stefania Gallini

Páginas 179-233

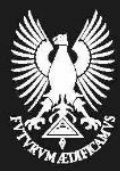




\title{
¿Qué hay de histórico en la Historiografía ambiental en América Latina?*
}

\author{
Stefania Gallini ${ }^{1}$ \\ Universidad Nacional de Colombia
}

Recepción: 18/02/2020

Evaluación: 15/06/2020

Aprobación: 21/07/2020

Artículo de Investigación e Innovación

https:/doi.org/10.19053/20275137.nespecial.2020.11586

\section{Resumen}

¿Cuánto ha aportado el campo de la historia ambiental latinoamericana a la historiografía de la región?, ¿qué tanto le ha importado a la historiografía ambiental latinoamericana incidir en la historiografía de la región?, ¿podría tejerse esta relación con mayor provecho para ambas? Este escrito

\footnotetext{
* El texto es producto parcial del proyecto de investigación Sustainable Farm Systems (SFS): Long-Term Socio-Ecological Metabolism In Western Agriculture, financiado por el Social Science and Humanities Research Council (Canada, Partnership Grant SSHRC no. 1-413226-1035-70606-8000. Principal investigator: Geoff Cunfer) y la Universidad Nacional de Colombia (no. 16830, duración 2012-20). Agradezco a Claudia Leal, Simón Uribe, Astrid Ulloa por muchas conversaciones sobre los temas aquí tratados, a todos los integrantes del proyecto SFS, pero en particular Manuel González de Molina, Enric Tello, Geoff Cunfer y Fridolin Krausman, y a SOLCHA en todas sus expresiones. A Anaclet Pons gracias por su impulso y sugerencias, y a dos evaluadores anónimos por comentarios que me ayudaron a mejorar el argumento.

1 Stefania Gallini, Ph.D. Historia de América, profesora asociada Universidad Nacional de Colombia. Grupo de investigación Historia, Ambiente y Política-Línea de Historia Ambiental. Dirección: Departamento de Historia, Edificio Manuel Ancízar, Ciudad Universitaria, Universidad Nacional de Colombia, Bogotá. Últimas 3 publicaciones: M. Ángel y S. Gallini, «Cooperación técnico-científica internacional en la construcción de redes de monitoreo atmosférico. El caso de Bogotá (1960-2016),» Letras Verdes. Revista Latinoamericana de Estudios Socioambientales, 25 (2019): 143-167; "The 'Zero Garbage affaire' in Bogotá (Colombia): politics, history and the future,» ed. Christof Mauch, RCC Perspectives: Transformations in Environment and Society, $\mathrm{n}^{\circ} 3$ (2016): 69-77; Stefania Gallini, ed., Semillas de Historia Ambiental (Bogotá: Editorial de la Facultad de Ciencias Humanas y Jardín Botánico de Bogotá «José Celestino Mutis», 2015). $\bowtie$ sgallini@unal.edu.co (1) https://orcid.org/0000-00025394-1854.
} 
le habla al público de la Historia desde una lectura crítica de la historiografía ambiental latinoamericana. Sugiere que ésta le ha indicado a la Historia la relevancia de una agencia histórica más amplia y compleja, pero a menudo se ha conformado con narrativas previsibles de limitado atractivo para historiadores sin intereses explícitos hacia la relación entre sociedades y ecosistemas. Argumenta que, al entrar en los últimos años a una etapa más madura, la historiografía ambiental latinoamericana ha abierto el camino hacia mejores preguntas sobre temas fundamentales de la historiografía latinoamericana, interrogantes y objetos que resultan renovadores tanto conceptual como metodológicamente. Aborda, a manera de ejemplos, los asuntos de la cuestión agraria y la construcción del Estado nacional, señalando sin embargo que persiste una necesidad de documentar y sistematizar mejor la metodología de la historia ambiental. Las Conclusiones avanzan hacia la hipótesis de que el Antropoceno, como lugar de controversia epistemológica y de desafío metodológico, puede representar un terreno de contribución original de la historia ambiental a la historiografía latinoamericana.

Palabras clave: historia ambiental, Antropoceno, historia de América Latina, cuestión agraria, historia de animales, historia de los residuos, construcción del Estado.

\section{What historical elements are there in environmental historiography in Latin America?}

\section{Abstract}

How much has environmental history contributed to the historiography of the region? How much has Latin American environmental historiography contributed to the historiography of the region? Could this relationship be cultivated for the benefit of both? This text addresses the public and talks about history based on a critical reading of Latin American environmental historiography. It suggests that historiography has indicated history the relevance of a wider and more complex historical agency, but it has 
often been formed by predictable narratives of limited appeal to historians without explicit interests regarding the relationship between societies and ecosystems. It is argued that, when entering the last years of a more mature phase, Latin American environmental historiography has opened a door to better questions concerning fundamental topics of Latin American historiography, questions and objects which seem conceptually, as well as methodologically, innovative. The article presents, by means of examples, topics related with agrarian issues and the construction of the nation state, nonetheless, noting that there is a necessity to better document and systematize the methodology of environmental history. The conclusions move towards the hypothesis that the Anthropocene, as a place of epistemological controversy and methodological challenge, may represent a territory of original contribution by environmental history to Latin American historiography.

Key Words: Environmental history, Anthropocene, Latin American history, agrarian question, history of animals, history of waste, construction of the state.

\section{Qu'y a-t-il d'historique dans l'historiographie environnementale en Amérique latine?}

\section{Résumé}

Quels ont été les apports de l'histoire environnementale latinoaméricaine à l'historiographie de cette région? À quel point l'historiographie environnementale latino-américaine a voulu influencer l'historiographie de la région? Cet article réfléchit sur l'histoire à partir d'une lecture critique de l'historiographie environnementale latino-américaine. On affirme ici que celleci montre à l'histoire l'importance d'une agence historique plus large et plus complexe, même si elle se contente souvent d'apportes des narratives prévisibles et peu attirantes pour les historiens qui ne sont pas forcément intéressés par le rapport entre les sociétés et les écosystèmes. Par ailleurs, l'historiographie environnementale latino-américaine a ouvert récemment la voie pour des questions concernant 
les problèmes fondamentaux de l'historiographie latinoaméricaine, des questions qui constituent une rénovation et conceptuelle et méthodologique. Par exemple, il est question ici du problème agricole et de la construction de l'État national, tout en signalant qu'il faut mieux systématiser la méthodologie de l'histoire environnementale. Enfin, on conclut que l'anthropocène en tant que sujet de controverse épistémologique et défi écologique, peut donner lieu à un ensemble de contributions de l'histoire environnementale à l'histoire latino-américaine.

Mots-clés: histoire environnementale, Anthropocène, histoire d'Amérique latine, question agricole, histoire des animaux, histoire des résidus, construction de l'État.

\section{Introducción}

El año 2020 marcó el comienzo de la tercera década de existencia autoconsciente de la historiografía ambiental latinoamericana, campo del conocimiento dedicado a indagar por las múltiples maneras en las que las sociedades humanas y el resto de la naturaleza han co-evolucionado juntos, afectándose y condicionándose mutuamente. Si la primera década del milenio (que quizá comenzó a mitad de los Noventa: excentricidades cronológicas frecuentes en la historia) fue la fundacional, y la segunda fue la del afianzamiento de este campo y su comunidad académica, cabe preguntarse ¿qué se puede esperar de la tercera?².

El que la Historia ambiental de América Latina haya avanzado y se pueda decir instalada en el escenario académico es vox populi. Si bien sería atrevido afirmar, como lo hace el historiador Paul Sutter al referirse a Estados Unidos, que "the field of environmental history has grown like kudzu on a hot

2 En otras dos ocasiones - en el pleno de las dos décadas mencionadas - he intentado ejercicios interpretativos similares, con los cuales me es inevitable dialogar: Stefania Gallini, «Invitación a La Historia Ambiental,» Tareas, n 120 (2002): 5-27, acceso el 20 de junio de 2020, https://www.redalyc.org/pdf/5350/535055631002.pdf; Stefania Gallini, «Historia, ambiente y política: el camino de la historia ambiental en América Latina,» Nómadas, nº 30 (2009): 92-102, acceso el 20 de junio de 2020, https://www. redalyc.org/pdf/1051/105112060008.pdf. 
July day» ${ }^{3}$, muchos indicadores y observadores señalan que también en América Latina el campo se ha ganado un lugar estable $^{4}$; sin embargo, estas observaciones suelen venir desde las entrañas de la historia ambiental misma, propuestas por autores (entre los que me incluyo) que son ellos mismos partícipes de la historia que quieren defender. Surge entonces la duda: ¿y si fuera la voz populi ambientis? Es decir, ¿no será una proyección autocomplaciente de los historiadores ambientales? ¿Cuánto ha aportado la historiografía ambiental latinoamericana a la historiografía de la región, y qué tanto le ha importado a la primera influir en la segunda? ¿Podría tejerse esta relación con mayor provecho para ambas?

Desde luego, plantearse esta clase de preguntas significa interpretar y sin duda limitar el campo de acción

3 Paul Sutter, «The World with Us: The State of American Environmental History,» Journal of American History 100, $\mathrm{n}^{\circ} 1$ (2013): 94, DOI: https://doi.org/10.1093/jahist/ jat095.95.

4 Así opinan por ejemplo Claudia Leal, John Soluri, y José A. Padua, Un pasado vivo: dos siglos de historia ambiental latinoamericana (Bogotá: Fondo de cultura económica y Universidad de Los Andes, 2019), 12-13. Vladimir Sánchez-Calderón y Jacob Blanc, «La historia ambiental latinoamericana: cambios y permanencias de un campo en crecimiento,» Historia Crítica, ${ }^{\circ} 74$ (2019): 5-6, DOI: https://doi. org/10.7440/histcrit74.2019.01. La apreciación se fundamenta en las actividades de la Sociedad Latinoamericana y Caribeña de Historia Ambiental - SOLCHA, las publicaciones científicas, las tesis de pre y posgrado, los grupos de investigación, la participación en congresos, la docencia universitaria. Observadores atentos a la evolución de este campo a nivel global opinan lo mismo, e in primis John R. McNeill, «The Historiography of Environmental History,» en The Oxford History of Historical Writing: Volume 5: Historical Writing Since 1945, ed. Axel Schneider and Daniel Woolf (Oxford: Oxford University Press, 2011), https://www.eolss.net/Sample-Chapters/C09/ E6-156-01-00.pdf. SOLCHA ha funcionado como cama-cuna, grupo de auto-ayuda, estímulo profesional, refugio académico, fuente de inspiración y entusiasmo, según las etapas de la vida de quien hacemos parte de ella. Para una historia de SOLCHA y de la consolidación institucional de la comunidad histórico-ambiental en América Latina ver: Martha Micheline Cariño Olvera, «Origen, fortalecimiento y perspectivas de la Sociedad Latinoamericana y Caribeña de Historia Ambiental (SOLCHA),» HALAC 1, $\mathrm{n}^{\circ} 1$ (30 de septiembre 2011): 9-28. https://www.halacsolcha.org/index. php/halac/article/view/157; Reinaldo Funes Monzote y Guillermo Castro Herrera, «La Historia Ambiental (hecha) en América Latina y el Caribe. Una actualización,» en Naturaleza en declive, ed. Reinaldo Funes Monzote (Valencia: Fundación Instituto de Historia Social, 2008), 39-62. Relevantes son también las autobiografías de algunos de los «pioneros» recogidas en la página web de SOLCHA, «Testimonios», y algunas entrevistas grabadas durante el VI Congreso SOLCHA en 2012 y disponibles en YouTube, por ejemplo David Sánchez-Ruíz, «VI SOLCHA - Regina Horta Duarte: Zoo geografía del Brasil,» YouTube, acceso el 20 de junio de 2020, https://www.youtube. $\mathrm{com} /$ watch?v=PYzDYmSkCPY\&list=PL4D3334F4C8C2E604\&index=4. 
de la historia ambiental, porque no solo es opinable que contribuir a la disciplina de la Historia sea su fin último o más preciado, sino que las raíces, la bibliografía y la biografía de los autores de la historia ambiental latinoamericana (aunque quizá no la latinoamericanista) ${ }^{5}$, indicarían más bien que su preocupación vertebral ha sido más la de tejer puentes con los estudios ambientales y del desarrollo, procurando incidir si acaso en las políticas públicas y la transformación social, que la de influir en la agenda y el oficio de la Historia ${ }^{6}$. Esta sería, de hecho y para algunos, la razón de ser de una historia ambiental para la región latinoamericana, y no (solamente) sobre ella, como reclama Patricia Clare ${ }^{7}$.

Cualquiera que sea la postura que se escoja frente a la razón de ser de este campo, es innegable que en su multidisciplinar DNA está también la intención de funcionar como agente disruptor de aquella Historia antropocéntrica,

5 Es una distinción que puso sobre la mesa Guillermo Castro Herrera, Funes Monzote y Castro Herrera, «La Historia Ambiental (hecha),».

6 No tengo mucha más evidencia que la de mi propia percepción subjetiva como observadora informada y empática, pero la categorización de los "campos ampliados» en los cuales Rivera y Chávez clasifican algunas obras influyentes de historia ambiental parecería corroborarlo. Patricia Rivera Castañeda y Refugio Chávez Ramírez, "La construcción de la historia ambiental en América,» Revista de El Colegio de San Luis 8, $\mathrm{n}^{\circ} 16$ (2018): 171-202, acceso 12 de enero de 2020, https:// www.redalyc.org/jatsRepo/4262/426259450008/index.html.

$7 \mathrm{Y}$ añade: «la historia ambiental latinoamericana tiene un fin utilitario explícito: dar cuenta de la exclusión social, económica y política de grupos humanos y a la vez (...) responder por los abusos a los ecosistemas de los cuales forma parte el ser humano». Patricia Clare Rhoades, "Un balance de la historia ambiental latinoamericana," Revista de Historia, 59-60 (2009): 186-87, acceso el 3 de julio de 2020, https://www. revistas.una.ac.cr/index.php/historia/article/view/3474. La evolución del Derecho internacional humanitarios y del Derecho ambiental internacional y el ya frecuente reconocimiento en tribunales latinoamericanos de la naturaleza como víctima brinda un nuevo marco de reflexión acerca no solo de la tensión ético-política del historiador ambiental, sino también de su capacidad de actual como historiador público en juicios llamados a determinar responsables de crímenes ambientales y definir medidas sancionatorias y de reparación, que van desde la restauración ecológica hasta acciones de rescate de la memoria ambiental de los pobladores afectados. Ver Gilmar Arruda y Roger Colácios, "Considerações ético-políticas na história (ambiental): escalas e o presentismo da devastação,» HALAC 9, n 2 (2019): 64-94, DOI: https:// doi.org/10.32991/2237-2717.2019v9i2. En Colombia el debate está ligado a la justicia transicional después de la firma del acuerdo de paz entre el gobierno y la guerrilla FARC-EP en 2016: Gabriela Eslava, «Naturaleza: ¿víctima del conflicto?,» Dejusticia blog, 8 de febrero de 2019, acceso 20 de junio de 2020; https://www.dejusticia.org/ naturaleza-victima-del-conflicto/. 
evolucionista y ciega frente a la crisis civilizatoria que representa en realidad la crisis ecológica ${ }^{8}$. En idioma Millenial se podría traducir por «hackear la Historia»".

La preocupación por la relación entre Historia (general) e Historia ambiental es compartida por varios autores ${ }^{10}$. En América Latina, Claudia Leal le ha dedicado un reciente ensayo programático, llegando a la conclusión que, por lo menos en el caso colombiano, "nuestro campo ha añadido aún poco al gran tratado de historia nacional $»^{11}$. Alejandro Tortolero ha tomado en cambio el camino del análisis metodológico, confrontando la historia ambiental en uno de los terrenos más sólidos de la historiografía latinoamericana,

8 Sobre la crisis ecológica como crisis civilizatoria sigue siendo inspiradora la relectura de uno de los primeros textos en español acerca de la historia ambiental (que en ese momento - 1993 - no estaba canonizada así) como camino transformador de la forma de entender la Historia: Manuel González de Molina y Joan Martínez Alier, «Historia y Ecología: Introducción,» Ayer, n 11 (1993): 11-18. El debate sobre los usos de la historia ambiental es estimulante: ver por ej. John R. McNeill, «The Uses of Environmental History: John R. McNeill,» Seeing the Woods a blog by the Rachel Carson Center, acceso 20 de junio de 2020, https://seeingthewoods. org/2017/03/01/the-uses-of-environmental-history/; Stefania Barca, «Uses of Environmental History, Stefania Barca,» Seeing the woods a Blog by The Rachel Carson Center, 5 de Abril de 2017, acceso 20 de junio de 2020, https://seeingthewoods. org/2017/04/05/uses-of-environmental-history-stefania-barca/; William Cronon, «The Uses of Environmental History,» Environmental History Review, 17 (1993): 1-22; Regina Horta Duarte, «Narrativa, Historia Ambiental y Sustentabilidad,» en Saberes para la sustentabilidad, eds. Martha Micheline Cariño Olvera y Lorella Castorena (Barcelona: Icaria, 2015), 195-206.

9 Sobre la cultura hacker y el sentido que ha tomado el vocablo, ver «Gabriella 'Biella' Coleman E., HackCurio: Decoding the Cultures of Hacking,» HackCurio (blog), acceso 6 de febrero de 2020, https://hackcur.io/. Agradezco a Luís Fernando Medina por esta sugerencia.

10 Por ejemplo, Sverker Sörlin and Paul Warde, «The Problem of the Problem of Environmental History: A Re-Reading of the Field,» Environmental History 12, n 1 (2007): 107-30, https://www.jstor.org/stable/25473035. Los autores concluyen que la marginalidad de la historiografía ambiental europea y también norteamericana en la historiografía general se debe en buena medida a la falta de un conjunto claro de problemas comunes al campo, percibido como fragmentado y reconocible más por su significación política que por su substancia académica.

11 Claudia Leal, "Aguzar la mirada colectiva, el gran desafío de la historia ambiental latinoamericana", Historia y sociedad, $\mathrm{n}^{\circ} 36$ (2019): 243-68. DOI: https:// doi.org/10.15446/hys.n36.71970., 249. El texto deriva de su intervención en la Mesa redonda de la III Escuela de Posgrado de SOLCHA (Anapolís, Goías - Brazil - 2017) que justamente se ponía la pregunta por la contribución de la historia ambiental a la historia general. Claudia Leal y otros, «Testimonios sobre la Tercera Escuela de Posgrados - SOLCHA,» SOLCHA, 2017, acceso 20 de junio de 2020, http://solcha.org/ images/Testimonios_Goi\%C3\%A1s.pdf. 
como lo es su filiación de la Escuela de Les Annales ${ }^{12}$. Y para quienes se dedican a este campo desde departamentos y programas curriculares en Historia, el problema se convierte en experiencia cotidiana, al tener que luchar por embeber la perspectiva histórico-ambiental en cursos de historia general, encontrar evaluadores de tesis y proyectos de investigación abiertos a pensar al ser humano como "un mamífero más», o participar desde la historia ambiental en eventos dedicados a efemérides clásicas de la Historia ${ }^{13}$.

Por las anteriores consideraciones, este escrito quiere hablarle al público de la Historia, lectores de revistas académicas como la presente, para contribuir a construir un puente y una legitimación crítica, ojalá no autocomplaciente, de la historia ambiental latinoamericana ${ }^{14}$. La argumentación se desarrolla en cuatro actos. En el primero, conejos y basura son los ejemplos que sirven para mostrar cuan amplia y compleja sea la agencia histórica sugerida por la historia ambiental. El segundo acto es un acto autocrítico, que apunta a señalar cómo la narrativa por lo general negativa y el interés de la historia ambiental, por dialogar más con los estudios ambientales y de la sostenibilidad, que con la historiografía no ha servido a integrar la perspectiva ambiental. La actual etapa

12 Alejandro Tortolero Villaseñor, «The Annales School and the Environmental History of Latin America,» Historia Caribe 12, n 30 (junio 2017): 301-40, DOI: http:// doi.org/10.15648/hc.30.2016.01.

13 Es una anotación autobiográfica. En la evaluación de un texto de esta autora, uno de los jurados consideró que el título "Un mamífero más» dado a una sección era irrespetuoso de la extraordinariedad del ser humano. Salió luego publicado como Stefania Gallini, Sofía De la Rosa, y Rigoberto Abello, «Historia Ambiental,» en Hojas de ruta. Guías para el estudio socioecológico de la alta montaña en Colombia, ed. Paula Ungar (Bogotá: Instituto Alexander Von Humboldt, 2015), edición en digital, acceso 20 de junio de 2020, http://www.humboldt.org.co/es/component/k2/item/826historia-ambiental.

14 La tarea está pendiente igualmente con otros campos: ¿qué le ha aportado por ejemplo la historia ambiental a la Biología de la conservación, o a los Estudios urbanos, o a las Ciencias de la Sostenibilidad? La deberá resolver quienes tengan militancia académica en estos campos. Para empezar, dos referencias sugerentes de la estrecha relación entre historia ambiental y ciencias de la sostenibilidad, y de sus complementarios paradigmas interpretativos son Martha Micheline Cariño Olvera y Lorella Castorena, ed., Saberes para la sustentabilidad (Barcelona: Icaria, 2015); Alf Hornborg y Carole L. Crumley, eds., The World System and the Earth System: Global Socioenvironmental Change and Sustainability since the Neolithic (Walnut Creek, CA: Left Coast Press, 2007). 
de madurez de la historiografía ambiental latinoamericana; sin embargo, muestra que está abierto el camino hacia mejores preguntas a temas álgidos de la historiografía latinoamericana, que resultan renovadoras tanto conceptual como metodológicamente. Como ejemplos, en el tercer acto se discute la temática de la cuestión agraria y en el cuarto la de la construcción del Estado nacional, señalando que persiste una necesidad de documentar y sistematizar mejor la metodología de la historia ambiental latinoamericana. Queda planteada en las Conclusiones la hipótesis de cómo innovar, y no solo adecuar la agenda de la historiografía latinoamericana a la luz de las perspectivas ambientales, razonando acerca del Antropoceno como lugar para construir una "historia rota y atormentada" que ayude a la comprensión del problema histórico de mayor envergadura actual.

Cabe un caveat metodológico. En comparación con mis propios intentos anteriores, este ejercicio interpretativo ha tropezado con el crecimiento exponencial de la bibliografía en la última década, una dificultad sensible para las que no nacimos con el don de la síntesis. La estrategia metodológica utilizada ha seguido un movimiento en tres pasos, cuyo comentario con cierto detalle puede resultar útil para documentar la "cocina» de la búsqueda y la revisión bibliográficas ${ }^{15}$. No sobra advertir que tampoco aspira a ser una exploración exhaustiva ni canónica.

En primer lugar, se escrutaron los recursos bibliográficos digitales Redalyc, SCOPUS, Dialnet, la Bibliografía On Line de Historia Ambiental Latinoamericana - BOHA, la sección Environmental History en la Oxford Research Encyclopedia of Latin American History, mi propia base bibliográfica Zotero $\mathrm{EH}$, el portal Academia.edu, y el portal multimedial del Rachel Carson Center Environment and Society ${ }^{16}$. De alguna

15 Los manuales de metodología en Historia tienden a ocuparse de Filosofía de la Historia más que de explicar las prácticas concretas. No así en la tradición académica anglosajona. Ver por ejemplo Dan Wewers, A Brief Guide to Writing the History Paper. (Cambridge, MA.: Harvard College Writing Center, 2007), edición en digital, acceso el 20 de junio de 2020, https://hwpi.harvard.edu/files/hwp/files/bg_writing_history.pdf.

16 Los primeros tres son bases de datos que por lo general cubren bien la producción bibliográfica latinoamericana, a menudo poco presente en índices bibliográficos 
utilidad ha resultado también la comunicación académica que circula en Twitter, especialmente bajo el \#envhist. Con ello se pretendió tener un panorama de temas, autores, lugares de producción, y problemas cubiertos por la bibliografía ${ }^{17}$.

El segundo paso fue la revisión de balances recientes de historiografía ambiental latinoamericana, un bien codiciado del cual el año 2019 ha sido pródigo. Vieron la luz, en particular, tres publicaciones de autoría múltiple que explícitamente se propusieron como estados del arte: la introducción y los ensayos reunidos en el libro editado por Leal, Soluri y Padua, Un pasado vivo: dos siglos de historia ambiental latinoamericana; el dossier de la revista HALAC sobre "Balances de HA», y la introducción de Sánchez y Blanc al de la revista Historia Crítica, titulado «Panorama actual de la historia ambiental latinoamericana» ${ }^{18}$.

internacionales: Redalyc - Red de Revistas Científicas de América Latina y El Caribe, España y Portugal; Dialnet; Scopus, que no es de acceso abierto. La enciclopedia digital de Oxford incluye a la fecha 38 artículos de temas de historia ambiental latinoamericana: Diego de Carvalho Cabral y otros, Environmental History - Oxford Research Encyclopedia of Latin American History. La BOHA - Bibliografía Online de Historia Ambiental Latinoamericana es una de las hazañas de SOLCHA y existe por iniciativa de Lise Sédrez, mientras que se mantiene gracias a la colaboración voluntaria de un grupo de solcheros. Desde 2019 cuenta con tres editoras. El portal Rachel Carson Center for Environment and Society, «Environment \& Society Portal» es el recurso digital más importante para la historia ambiental internacional.

17 Resultó un fracaso intentar procesar este corpus documental (organizado en Zotero) con el software Voyant Tools para obtener una «lectura distante» que ayudara a orientar la interpretación, porque pulir el conjunto documental trilingüe (español, portugués e inglés) que se obtuvo fue imposible en los tiempos limitados para esta investigación bibliográfica. Ver Corporation for Digital Scholarship. Zotero, 200, acceso el 20 de junio de 2020. https://www.zotero.org/; Sinclair, Stéfan, and Geoffrey Rockwell. Voyant Tools. Acceso el 8 de febrero de 2020. https://voyant-tools.org/; «Análisis de corpus con Voyant Tools de Silvia Gutiérrez,» The Programming Historian, acceso el 20 de junio de 2020, https://programminghistorian.org/es/lecciones/analisis-voyant-tools. Otro impedimento fue la inaccesibilidad de un plugin para visualizar colecciones de Zotero en Voyant Tools, como lo hacía Jo Guldi and Cora Johnson-Roberson, Paper Machines, visualize thousands of texts with the click of a button, 2012, acceso el 3 de julio de 2020. http:// papermachines.org/.

18 Leal, Soluri, y Padua, Un pasado vivo; Sandro Dutra e Silva, Marina Miraglia y Wilson Picado, «Balances de Historia Ambiental en América Latina,» HALAC 9, $\mathrm{n}^{\circ} 2$ (19 diciembre 2019): 09-15, DOI: https://doi.org/10.32991/2237-2717.2019v9i2. Sánchez-Calderón and Blanc, "La historia ambiental latinoamericana». Existen otras contribuciones para pensar la historia ambiental latinoamericana, pero no son propiamente síntesis historiográficas. Ver por ej. Guillermo Castro Herrera, "América Latina: Historia ambiental y crisis global,» en Por una historia ambiental latinoamericana: aportes para el estudio de la sociedad y la naturaleza en la era del Antropoceno, ed. Adrián Gustavo Zarrilli (Buenos Aires: Teseo, 2016). 
En tercer lugar, se tomaron en seria consideración varios ensayos de síntesis de la historia ambiental latinoamericana publicados en los últimos años, un lujo del cual las primeras generaciones de cultores de este campo evidentemente no gozaron ${ }^{19}$. Esto, junto con el acumulado de docencia en el cual he ido yo misma ensayando tópicos y referencias ${ }^{20}$, permitió caminar sobre terreno pisado.

\section{Actores insólitos para problemas importantes}

A menudo en las revistas de historia ambiental aparecen títulos que, no lo dudo, hacen sonreír a quienes los lean desde afuera del campo: «Attacked by Excrement: The Political Ecology of Shit in Wartime and Postwar Tokyo» ${ }^{21}$, por ejemplo. $\mathrm{O}$ «El conejo europeo en Chile: historia de una invasión biológica» ${ }^{22}$. Residuos y animales son dos ejemplos ilustrativos del cambio de mirada que pretende sugerir la historia ambiental a la indagación histórica en general, otorgando estatus de actores

19 Las síntesis son casi todas en inglés: Christopher R. Boyer, «Latin American Environmental History," en Oxford Research Encyclopedias: Latin American History. (Oxford: Oxford University Press, 2016), 1-24, edición en digital, acceso el 20 de junio de 2020, https://www.academia.edu/28965338/Latin_American_Environmental_ History; Myrna Santiago, «Environmental History,» en Oxford Bibliographies Online: Latin American Studies. (Oxford: Oxford University Press, 2013), edición en digital, acceso el 20 de junio de 2020, http://www.oxfordbibliographies.com/view/document/ obo-9780199766581/obo-9780199766581-0077.xml; Lise F. Sédrez, «Environmental History of Modern Latin America," en A Companion to Latin American History, , ed. Thomas Holloway (Malden, MA: Blackwell, 2008), 443-60; Lise F. Sédrez, «Latin American Environmental History: A Shifting Old/New Field,» en The Environment and World History, eds. E. Burke III and K. Pomeranz (Berkeley and Los Angeles: The University of California Press, 2009), 255-275; Shawn W. Miller, «Latin America in Global Environmental History," en A Companion to Global Environmental History, eds. John R. McNeill y Erin S. Mauldin (Wiley Blackwell: Hoboken, NJ, 2012), 116-31; Shawn W. Miller, An Environmental History of Latin America (New York: Cambridge University Press, 2007); Leal, Soluri y Padua, Un pasado vivo.

20 Dicté mi primer curso en Historia ambiental latinoamericana en 2002 en la Universidad Nacional de Colombia, sede Bogotá. Aprovecho para reconocer mi deuda con las varias generaciones de estudiantes de esta Alma Mater que me acompañaron en mis exploraciones bibliográficas.

21 Paul Kreitman, «Attacked by Excrement: The Political Ecology of Shit in Wartime and Postwar Tokyo,» Environmental History 23, n 2 (1 April 2018): 342-66, acceso el 20 de junio de 2020, DOI: http://doi.org/10.1093/envhis/emx136.

22 Pablo Camus, Sergio Castro y Fabián Jaksic, «El conejo europeo en Chile: historia de una invasión biológica,» Historia 41, nº 2 (2008): 305-39, acceso el 20 de junio de 2020, http://revistahistoria.uc.cl/index.php/rhis/article/view/10696/9876. 
(o actantes, según las preferencias epistemológicas ${ }^{23}$ ) a entidades insólitas en los relatos históricos, como excrementos y conejos. Estos, sostienen los historiadores ambientales, participaron de muchas maneras en moldear la existencia humana tal como la conocemos. Los excrementos humanos fueron un componente fundamental, junto a los desechos animales y en general a los residuos, del metabolismo urbano, un flujo de salida de la ciudad que tuvo comercio, fue ejercicio de poder, sirvió para trazar demarcaciones de clase, género y etnias, fue protagonista de políticas higiénicas y de salud pública, fue objeto de experimentación tecnológica y circulación internacional de saberes ingenieriles y médicos, y también representó por siglos un vínculo vital entre ciudad y campo, que lo recibía como fertilizante. Todavía conocemos poco de esta historia desechada para América Latina, pero basta con detenerse a ojear la mirada amplia que los Discard Studies proponen para captar las inmensas posibilidades del estudio de los residuos y comprender algunas de las dinámicas más profundas de la historia de las sociedades humanas en su interacción con el resto de la naturaleza ${ }^{24}$.

23 Bruno Latour, Reensamblar lo social: una introducción a la teoría del actor-red (Buenos Aires: Manantial, 2008).

24 Para una visión panorámica y crítica de los estudios de los residuos, ver los recursos digitales Simone M. Müller, «The Life of Waste,» Environment \& Society Portal: Virtual Exhibitions, $\mathrm{n}^{\circ} 3$ (2018), acceso el 20 de junio de 2020, DOI: http:// doi.org/10.5282/rcc/8452; Max Liboiron, Discard Studies, acceso 20 de junio de 2020, https://discardstudies.com/; Christof Mauch, ed., «Out of Sight, Out of Mind: The Politics and Culture of Waste," RCC Perspectives: Transformations in Environment and Society, $\mathrm{n}^{\circ} 1$ (2016), acceso el 3 de julio de 2020, DOI: https://doi.org/10.5282/ rcc/7388. Para una introducción a la historia ambiental de la basura ver Sabine Barles, «History of Waste Management and the Social and Cultural Representations of Waste,» en The Basic Environmental History, eds. Mauro Agnoletti y Simone Neri Serneri (Geneva: Springer, 2014), 199-226. Una inspiradora historia social de la basura es Susan Strasser, Waste and Want: A Social History of Trash (New York: Henry Holt and Company, 2000). Para América Latina ver Lise F. Sédrez y Regina Horta Duarte, «El muro y la hiedra: narrativas ambientales de un continente urbano," en Un pasado vivo: dos siglos de historia ambiental latinoamericana, eds. Claudia Leal, John Soluri y José A. Padua (Bogotá: Fondo de cultura económica y Universidad de Los Andes, 2019), 165-67. María Fernanda Solíz Torres, «Ecología política y geografía crítica de la basura en el Ecuador," Letras Verdes. Revista Latinoamericana de Estudios Socioambientales, $n^{\circ} 17$ (marzo 2015): 4-28; Frank Molano Camargo, «El relleno sanitario Doña Juana en Bogotá: la producción política de un paisaje tóxico, 1988-2019,» Historia Crítica, $\mathrm{n}^{\circ} 74$ (2019): 127-49, acceso el 20 de junio de 2020, DOI: http://https//doi.org/10.7440/histcrit74.2019.06; Jorge Lossio, Acequias y gallinazos: salud ambiental en Lima del siglo XIX (Lima: IEP, Instituto de Estudios Peruanos, 2003); Kathleen Kole de Peralta, «Mal Olor and Colonial Latin 
En cuanto a los conejos, cuentan Camus, Castro y Jaksic que, similar a lo que le ocurrió a ratas, marranos y malas hierbas -protagonistas del intercambio colombino que Alfred Crosby canonizó como conquista biológica ${ }^{25}$ - actuaron como aliados inconscientes de dinámicas imperiales que resultaron exitosas, en la medida en que lograron modificar los paisajes y las cadenas ecológicas, y no solo las relaciones sociales o la organización política. Los conejos europeos fueron invitados probablemente desde mitad del siglo XVIII, en plena época colonial, para poblar Chile por ser proveedores de carne y pieles. Dos siglos después, se habían transformado en extraordinaria plaga a expensa del zorro nativo.

La historia de estos animales comunes puede parecer anecdótica, pero en cambio enseña un pilar fundamental de la perspectiva ambiental: los seres humanos comparten su historia con muchas otras especies, que no solo son comidas, cultivadas, extraídas o modificadas por las personas, sino que tienen su propia historia. Se reproducen y establecen en el territorio no solo porque haya intereses comerciales en que esto suceda, sino de acuerdo a su biología, como anota Melville en su conocida Plaga de ovejas en el Valle de Mezquital, en México. Conocer la forma en la que el ganado menor introducido por los conquistadores se reproducía le permite a Melville establecer que, los números de cabezas que aparecen en los registros archivísticos hablan de una verdadera irrupción de ungulados, con todo lo que aquello acarrea para la compactación del suelo, y de allí la reducción de la fertilidad de la tierra, y el empobrecimiento de los pobladores antiguos del Valle central de México y la estabilización del sistema del pastoralismo colonial ${ }^{26}$.

\footnotetext{
American History: Smellscapes in Lima, Peru, 1535-1614,» Hispanic American Historical Review 99, $\mathrm{n}^{\circ} 1$ (1 February 2019): 1-30, acceso el 20 de junio de 2020, DOI: https//doi.org/10.1215/00182168-7287951.

25 Alfred W. Crosby, The Columbian Exchange; Biological and Cultural Consequences of 1492 (Westport, Conn., Greenwood Pub. Co., 1972); Alfred W. Crosby, Imperialismo Ecológico (Barcelona: Crítica, 1988).

26 Elinor G.K Melville, Plaga de Ovejas: Consecuencias Ambientales de La Conquista de México (México, D.F.: Fondo de Cultura Económica, 1999); Boyer, «Latin American Environmental History,» 6-7. Hay controversia acerca de los cálculos de Melville y de su tesis de degradación ambiental en el Valle Central, ver Richard Hunter,
} 
Cualquiera que mire a su alrededor hoy aceptará que los animales -de todos los tamaños, razas e importancia económica- ocupan un lugar extraordinario en la existencia humana. Pero esta visibilidad animal es fruto de una sensibilidad reciente, lo cual explica porque sea solamente en años recientes cuando la historiografía le ha abierto sus puertas $^{27}$. En América Latina, la historia de los animales se ha ido ensanchando desde los iniciales estudios sobre bovinos, ovinos y otra fauna entendida como recurso productivo, hasta interesar animales urbanos, habitantes de los zoológicos, aves migrantes o jaguares sobreviviente, mosquitos, y bagres, entre muchos ${ }^{28}$.

«Positionality, Perception, and Possibility in Mexico's Valle Del Mezquital,» Journal of Latin American Geography 8, $n^{\circ} 2$ (23 august 2009): 49-69, acceso el 20 de junio de 2020, DOI: https://doi.org/10.1353/lag.0.0059.

27 En la Historia ambiental norteamericana y europea la Animal History ya creció tanto que se considera un campo autónomo, pero no todavía en América Latina. Ver Lauren Derby, «Bringing the Animals Back in: Writing Quadrupeds into the Environmental History of Latin America and the Caribbean,» History Compass 9, $\mathrm{n}^{\circ}$ 8 (2011): 602-21, acceso el 12 de enero de 2020, https://www.academia.edu/5900624/ Bringing_the_Animals_Back_in_Writing_Quadrupeds_into_the_Environmental_ History_of_Latin_America_and_the_Caribbean.; Germán Vergara, "Animals in Latin American History," en Oxford Research Encyclopedia of Latin American History: Environmental History (Oxford: Oxford University Press, 2018), acceso el 20 de junio de 2020, DOI: https://doi.org/10.1093/acrefore/9780199366439.013.436. Horta enmarca magistralmente el tema en la historia de la historiografía brasileña, recuperando autores clásicos de la primera mitad del siglo XX que prestaron atención a los animales, antes de la desaparición del tema en las décadas de 1960-90: Regina Horta Duarte, "História dos animais no Brasil: tradições culturais, historiografia e transformação,» HALAC 9, $\mathrm{n}^{\circ} 2$ (13 December 2019): 27-29, acceso el 20 de junio de 2020, DOI: http://doi.org/10.32991/2237-2717.2019v9i2.p16-44. Interesantes los podcast Sean Kheraj, «Nature's Past Episode 56: Animal Metropolis, Podcast,(29 Mayo 2017), MP3, 25:31,» NiCHE Network in Canadian Environmental History, acceso el 9 de febrero de 2020, http://niche-canada.org/2017/05/29/natures-pastepisode-56-animal-metropolis/; Oosthoek, Jan K. y Chris Pearson, "Canine City: Dogs and Humans in Urban History,» en Environmental History Resources, Podcast 47, 19 noviembre 2012, MP3, acceso el 20 de junio de 2020. https://www.eh-resources. org/podcast- $47 /$.

28 Shawn Van Ausdal y Robert W. Wilcox, «Un continente cubierto de pasto: ganadería y transformación del paisaje,» en Un pasado vivo: dos siglos de historia ambiental latinoamericana, ed. Claudia Leal, John Soluri y José A. Padua (Bogotá: Fondo de cultura económica y Universidad de Los Andes, 2019), 200-22; Stefania Gallini, «El Atila del Ganges en la ganadería colombiana,» Nómadas 22 (2005): 186-97, acceso el 3 de julio de 2020, http://nomadas.ucentral.edu.co/index.php/27articulos-22/385-El-Atila-del-Ganges-en-la-ganader\%C3\%ADa-colombiana; Shawn Van Ausdal, «Potreros, ganancias y poder. Una historia ambiental de la ganadería en Colombia, 1850-1950», Historia Crítica, 39E (2009): 126-49, acceso el 3 de julio de 2020, DOI: https://doi.org/10.7440/histcrit39E.2009.07; Reinaldo Funes Monzote, «Facetas de la interacción con los animales en Cuba durante el siglo XIX: los bueyes 
Excrementos y conejos son entonces nada más que dos ejemplos, que se podrían multiplicar casi ad infinitum para tratar de convencer a los apasionados de la nueva historia cultural, a los secuaces de la historia conceptual, a los irreducibles de la historia económica y a los apóstoles de la historia política, que buscar en las fuentes documentales y otorgarle agencia histórica a agua, suelos, insectos, lluvias, paisajes, aves, y demás participantes del circo de la historia ambiental puede cambiar su forma de entender de quién y para qué es la Historia ${ }^{29}$.

Las madres de adolescentes, sin embargo, sabemos que nada es menos exitoso que intentar convencer a punta de ejemplos "sugerentes» a sujetos, como los adolescentes y los historiadores, por lo general desconfiados de la utilidad de

en la plantación esclavista y la Sociedad Protectora de Animales y Plantas,» Signos Históricos, $\mathrm{n}^{\circ} 16$ (2006): 80-110, acceso el 3 de julio de 2020, http://www.redalyc. org/resumen.oa?id=34401604; Regina Horta Duarte, «"El zoológico del porvenir": narrativas y memorias de nación sobre el Zoológico de Chapultepec, Ciudad de México, siglo XX,» Historia Crítica, ${ }^{\circ} 72$ (2019): 93-113, acceso el 3 de julio de 2020, DOI: https://doi.org/10.7440/histcrit72.2019.05; Camilo Quintero Toro, Birds of Empire, Birds of Nation. A History of Science, Economy, and Conservation in United States-Colombia Relations (Bogotá: Universidad de los Andes, 2012); José Andrade Franco, José Augusto Drummond y Fernanda Pereira de Mesquita Nora, «History of Science and Conservation of the Jaguar (Panthera Onca) in Brazil,» HALAC 8, $\mathrm{n}^{\circ} 2$ (10 diciembre 2018): 42-72, acceso el 3 de julio de 2020, DOI: https:// doi.org/10.32991/2237-2717.2018v8i2.p42-72.; John R. McNeill, Mosquito Empires: Ecology and War in the Greater Caribbean, 1620-1914 (Cambridge: Cambridge University Press, 2010) ; Juan David Delgado Rozo, «"Nuestras pobres vacas de otros tiempos": refinamiento ganadero y cambio de paisaje en la Sabana de Bogotá, 18601880,» en Semillas de Historia Ambiental, ed. Stefania Gallini (Bogotá: Universidad Nacional de Colombia y Jardín Botánico de Bogotá, 2015); Micheline Cariño Olvera and Mario Monteforte, "An Environmental History of Nacre and Pearls: Fisheries, Cultivation and Commerce,» Global Environment 2, no 3 (2009): 48-71. DOI: https:// doi.org/10.3197/ge.2009.020303; Graciela Pintos, Martha Micheline Cariño Olvera y Raquel Briseño-Dueñas, "Relaciones históricas entre las tortugas marinas y las sociedades del finis terra bajacaliforniano,» HALAC $3, \mathrm{n}^{\circ} 1$ (30 septiembre 2013): 89-115, acceso el 3 de julio de 2020, https://www.halacsolcha.org/index.php/halac/ article/view/170; Luis Angel Trujillo, Carlos Rodríguez y Confucio Hernández, Piraiba: ecología ilustrada del gran bagre amazónico (Bogotá: Tropenbos, 2018); Elisabet Prudant, «Del caballo a la electricidad: imaginario ambiental y tecnológico en la transformación del sistema tranviario chileno a fines del siglo XIX,» Historia Crítica, $\mathrm{n}^{\circ} 74$ (2019): 41-64, acceso el 3 de julio de 2020, DOI: https://doi.org/10.7440/ histcrit74.2019.03; R. Sanchez, "Animales en la ciudad: vecinos ocultos,» Ilé: Anuario de Ecologia, Cultura y Sociedad 3, $\mathrm{n}^{\circ} 3$ (2003): 213-25.

29 Interesantes los apuntes críticos de Sutter acerca del concepto de «agencia» en la historia ambiental: Sutter, «The World with Us,» 98. 
consejos que no vengan de su grupo de pares más cercano. Más eficaz resulta, en ambos casos, hacer un esfuerzo de empatía y tratar de adoptar el punto de observación del otro. ¿Por qué debería un historiador interesado en aristas distintas a la ambiental detenerse a conocer, y ojalá apropiarse, lo que ha producido la comunidad que a esto se dedica? O, parafraseando a Leal, Soluri y Padua, ¿qué es «lo histórico» en la historia ambiental de América Latina? ${ }^{30}$.

\section{Hacia una "historia rota y atormentada"}

Espero no resulte en un ejercicio de autocrítica a la soviética (con condena a expulsión automática del gremio) reconocer, con base en la revisión bibliográfica explicada al comienzo, que la historiografía ambiental latinoamericana muy a menudo no ha estado guiada por preguntas que la comunidad histórica general pueda reconocer como propias. De hecho, muchos problemas en la agenda investigativa de la historia ambiental latinoamericana no son tales para los demás practicantes del oficio de historiador: ¿cómo se transformó el paisaje durante la Colonia? ¿Cuándo ha surgido una política de conservación de ecosistemas vulnerables y de protección de especies en extinción? ¿Cuál ha sido el impacto ambiental de la minería? ¿Cómo se manifestaron las variaciones climáticas en el pasado? ¿Eran ambientales los conflictos por la tierra que tanto aparecen en los registros archivísticos? ¿Quién se benefició de los cambios en los regímenes hídricos de la modernización hidroeléctrica? ¿Cómo influyó la representación de la naturaleza tropical en la deforestación de las selvas? ¿Qué

30 La pregunta que se ponen ellos es: «qué es "lo latinoamericano" en la historia ambiental de América Latina?» Su respuesta es: «las herencias del colonialismo ibérico, la formación y persistencia de los estados nacionales decimonónico, los intercambios interoceánico y la tropicalidad». Leal, Soluri y Padua, Un pasado vivo, 19. Similar interrogación la puso también Germán Palacio-Castañeda, "Is There Any "Latin" in the Latin American Environmental History? New Challenges for the Consolidation of a Regional Intellectual Community," HALAC 1, $\mathrm{n}^{\circ} 2$ (2012): 157-79. Su respuesta va en el sentido de una necesaria convergencia de agendas investigativas latino y norte-americana, llamado que refuerza en Germán PalacioCastañeda, "An Eco-Political Vision for an Environmental History: Toward a Latin American and North American Research Partnership,» Environmental History 17, ${ }^{\circ}$ 4 (1 october 2012): 725-43, acceso el 3 de julio de 2020, DOI: https://doi.org/10.1093/ envhis/ems081. 
le pasó a los desiertos o a los ecosistemas marinos durante los siglos de construcción de Estados y economías nacionales? ¿Cómo impactó la Revolución Verde en los saberes campesinos tradicionales?

Todas son preguntas válidas e importantes, y han contribuido a escribir páginas iluminantes de lo que sabemos de la historia ambiental de América Latina. Pero sólo le importan a quienes tenga un visor ambiental puesto en su mirada a la Historia (y la vida), y la historiografía actual en su mayoría no lo tiene. Uno de los varios indicadores es, por ejemplo, la inclusión de un capítulo ambiental en las recientes compilaciones generales de la historia de la región, pero separado de las narrativas generales, un apéndice que finalmente se puede poner y quitar al gusto. Así se puede interpretar la valiosa síntesis de la historia ambiental contemporánea latinoamericana de Sedrez en el Companion to Latin American History o el capítulo de Rodríguez Becerra sobre la historia del ambientalismo latinoamericano y caribeño en la Historia General de América Latina de la UNESCO ${ }^{31}$. Quien ha hecho el análisis en compendios de historias nacionales ha llegado a la misma conclusión ${ }^{32}$. Otro de los indicadores puede ser la presencia y frecuencia de términos importantes para la historia ambiental latinoamericana en los compendios de historia general de América Latina, y en las revistas de Historia de y sobre la región. Tómese, por ejemplo, los términos Revolución Verde, conflictos socio-ambientales, transiciones energéticas, agroecosistema, conservación, bosques y, por supuesto, cambio climático. Su recurrencia en textos de historia general se puede buscar con facilidad porque se trata de un corpus documental disponible digitalmente. El resultado de la búsqueda es contundente: la historia ambiental

31 Sédrez, «Environmental History of Modern Latin America»; Manuel Rodríguez Becerra, «El ambientalismo en América Latina y el Caribe,» en Historia General de América Latina. Vol. VIII: América Latina desde 1930, ed. Marco Palacios, (París: UNESCO, 2008), 551-76.

32 Leal, "Aguzar la mirada»; Horta Duarte, «História Dos Animais No Brasil»; con referencia a Europa y Norteamérica, Sörlin and Warde, «The Problem of the Problem». 
ha crecido en un nicho ${ }^{33}$. Sus palabras claves no aparecen en la lengua vernácula de la disciplina histórica.

No tendría por qué ser así. La historiografía ambiental, que es una caja de Pandora en la que se logran acomodar a gusto geógrafos, agrónomos, sociólogos, biólogos, historiadores y antropólogos -para citar identidades disciplinares frecuentes entre autores de este campo-sabe participar de la indagación histórica general $\mathrm{y}$, en este acometido, ha resultado más original cuando ha superado su probablemente fisiológica tendencia a la "narración a teleología negativa», como la llama Bevilacqua:

[...]una especie de historia progresiva invertida. Una nueva narración, teleológicamente negativa, cuyo objetivo es seleccionar los fenómenos y procesos del pasado para encontrar en los problemas ambientales del presente el resultado inevitable y coherente de aquellos. No es que esta historia no tenga su utilidad. (...) [pero] La naturaleza de las relaciones reales entre los hombres y su entorno no siempre se puede ceñir a marcos de coherencia geométrica. Es una historia mucho más rota y atormentada ${ }^{34}$.

Esta tendencia a la unilinealidad histórica para explicar transformaciones ambientales negativas, que ha venido llamándose entre analistas de habla inglesa declensionist narrative $^{35}$, y entre latinoamericanos y latinoamericanistas

33 Por cierto, ya lo señalaba en 2005 John Soluri, «History's Freaks of Nature,» Environmental History 10, $\mathrm{n}^{\circ} 1$ (2005): 94-95, acceso el 3 de julio de 2020, https:// www.jstor.org/stable/3985856.

34 Piero Bevilacqua, Demetra e Clio: uomini e ambiente nella storia (Roma: Donzelli, 2001), 6-7. Traducción propia.

35 Un ejemplo de esta discusión con referencia a la interpretación ambiental del Dust Bowl en las grandes planicies norteamericanas en los años 192 es David Moon, "The Grasslands of North America and Russia,» en A Companion to Global Environmental History, eds. John R. McNeill and Erin S. Mauldin, (Wiley Blackwell: Hoboken, NJ, 2012), 250. En ámbito urbano, significó enfocarse en cómo «la agencia humana contribuyó, a través de la construcción de ciudades y otras acciones (i.e. la industrialización) a dañar, transformar o destruir la naturaleza». Jordan Bauer y Martin V. Melosi. "Cities and the Environment," en A Companion to Global Environmental History, eds. John R. McNeill and Erin S. Mauldin (Wiley Blackwell: Hoboken, NJ, 2012), 363. (traducción propia). Este énfasis, recuerdan los autores, ha privilegiado una mirada internalista a la ciudad, con escasa atención a su relación externa, con el campo y los alrededores. 
«historias trágicas» ${ }^{36}$, podría decirse una variante ambiental de la versión Whig de la Historia, aquella que en la tradición británica suponía el pasado y el futuro atados en un inevitable camino de progreso pavimentado por eventos que, leídos en cadena, revelaban la clave explicativa uno del otro.

Para oficiantes de la Historia con intereses distintos a la indagación de la relación entre sociedades y ecosistemas, las narraciones trágicas tan comunes en una primera etapa de la historia ambiental $-\mathrm{y}$ que siguen teniendo mucho espacio en las publicaciones en este campo en América Latinaprobablemente resulten de limitado atractivo. La solución, desde luego, no puede estar en un revisionismo históricoambiental per se, por el gusto de crear contracorrientes académicas más cercanas a otras perspectivas históricas. La historia ambiental debe seguir intentando explicar las razones, las dinámicas, las dimensiones de las transformaciones socio-ambientales. En este sentido, siguen haciendo falta indagaciones factuales sobre muchísimos hechos ambientales que se pueden catalogar, con tranquilidad epistémica, como desastrosos o por lo menos perjudiciales para las complejas relaciones sociedad-naturaleza ${ }^{37}$; sin embargo, parece urgente propender por una historiografía ambiental de la complejidad, a espejo de su propia materia, esforzándose

36 Mark Carey, «Latin American Environmental History: Current Trends, Interdisciplinary Insights, and Future Directions," Environmental History, $\mathrm{n}^{\circ} 14$ (2009): 221-52; Sánchez-Calderón and Blanc, «La historia ambiental latinoamericana,» 7-9.

37 Por ello son buenas noticias las investigaciones, para citar algunos ejemplos, sobre los conflictos socio-ambientales por el avance de la frontera del agribusiness (soja) en el norte de Argentina, o las que reconstruyen la degradación del paisaje lacustre en el Chile central, o las que empiezan a mapear la lucha de "resistencia» de las abejas de Costa Rica desde la década de 1940 enfrentando plagas y competencia de la caña para la producción de mieles. Adrián G. Zarrilli, «Nuevas formas de politización y conflictos socio-ambientales en el mundo rural argentino: las provincias de Chaco y Formosa frente a los procesos de deforestación y avance de la frontera agrícola (1980-2010),» HALAC 6, n ${ }^{\circ} 1$ (9 Septiembre 2016): 11-29, DOI: doi.org/10.5935/2237-2717.20160002; Pablo Pedreros Troncoso, Fernando Torrejón, Denisse Álvarez, y Roberto Urrutia, «Reconstruyendo la degradación ambiental del lago Vichuquén, región del Maule, Chile, mediante el uso de registros históricos-documentales,» HALAC 9, $\mathrm{n}^{\circ} 1$ (18 Junio 2019): 149-77, DOI: https://doi.org/10.32991/2237-2717.2019v9i1.p149-177; Maximiliano López-López, «Guerra de mieles: hipótesis para una historia ambiental de la miel de abeja en Costa Rica (1906-2014),» HALAC 8, $\mathrm{n}^{\circ} 2$ (10 diciembre 2018): 121-51, DOI: https://doi.org/10.32991/2237-2717.2018v8i2. 
por reconstruir aquella "historia rota y atormentada» que menciona Bevilacqua, y aportar desde allí a la comprensión de problemas históricos de interés general.

La observación de la producción historiográfica más reciente sugiere que posiblemente esta etapa de mayor madurez le ha llegado a la historiografía ambiental de América Latina. Es una temporada de caminos menos previsibles, fracasos que resultan ganancias, errores reveladores y, sobre todo, preguntas mejor atinadas. La evidencia se encuentra en el abordaje de muchos temas, pero prefiero limitarme a los que mejor conozco, que me parece tienen poder explicativo, y que son centrales en la historiografía latinoamericana: la cuestión agraria y la construcción del Estado nacional.

\section{Preguntas históricas con respuestas ambientales: la cuestión agraria}

«Cuestión» deriva del latino quaerere, que significa buscar, tratar de encontrar. Hay cuestiones que son problemas, como la cuestión homérica - la dificultad de atribución de la autoría de los poemas épicos a un único autor llamado Homero- y la "cuestión agraria». Al primero que le pareció un problema fue, en 1899, Karl Kautsky. El intelectual europeo y figura central del pensamiento marxista y de la socialdemocracia indicaba con La cuestión agraria la dificultad de definición del rol del campo y del campesinado en el desarrollo del capitalismo (o más bien al revés, el rol del desarrollo capitalista en el campo y el destino del campesinado en la proletarización coexistencial al capitalismo) ${ }^{38}$.

Desde entonces y grosso modo en los mismos términos de Kautsky, el agro le ha seguido pareciendo un problema a una parte importante de las ciencias sociales. Su interrogación intelectual ha vivido épocas doradas y olvidos prolongados,

38 Karl Kautsky, La cuestión agraria (Madrid: Marxists Internet Archive [1903] 2015), edición en digital, acceso el 3 de julio de 2020, https://www.marxists.org/ espanol/kautsky/1899/kautsky-la-cuestion-agraria.pdf. Los párrafos siguientes le deben mucho a las lecturas y conversaciones con Simón Uribe durante el desarrollo de la investigación Sustainable Farm System, y aprovecho aquí para agradecerle. 
pero, como las malas hierbas y las buenas amigas, nunca ha desaparecido del escenario ${ }^{39}$. Esto ha sido especialmente cierto en América Latina, y no solo por la constante y políticamente ruidosa presencia de campesinos en la región aún en época de furibundo neoliberalismo ${ }^{40}$, sino por la importancia que precisamente el campesinado latinoamericano ha tenido en la reflexión teórica alrededor de la cuestión agraria en general. Lo recuerda Roseberry en un texto viejo, de más de 25 años (1993), pero todavía válido, y Soluri en un ensayo joven, de menos de 1 año (2019), que amerita lectura atenta ${ }^{41}$. Escribiendo justo a mitad entre estas dos apreciaciones, una voz atenta al mundo rural e indígena latinoamericano, la del antropólogo e historiador chileno José Bengoa, observaba con respecto a los estudios agrarios:

[...]la lectura de textos que fueron de la mayor trascendencia en los años sesenta hoy en día no son, con excepciones, otra cosa que asuntos de interés para el análisis de la historia de las ideas. Al revisar la literatura uno se encuentra ante debates que hoy suenan pasados de moda, sin importancia actual e incluso desmedidos. Más aún la inercia de los

39 Cristóbal Kay, «Algunas reflexiones sobre los estudios rurales en América Latina,» Íconos. Revista de Ciencias Sociales, 29 (2007): 31-50, acceso el 3 de julio de 2020, http://www.flacso.org.ec/docs/i29kay.pdf; A. Haroon Akram-Lodhi y Cristóbal Kay, «Surveying the Agrarian Question (Part 1): Unearthing Foundations, Exploring Diversity," Journal of Peasant Studies 37, $\mathrm{n}^{\circ} 1$ (2010): 177-202. DOI: https://doi. org/10.1080/03066150903498838. José Bengoa, «25 Años de estudios rurales,» Sociologías 5, n 10 (2003): 36-98, acceso el 3 de julio de 2020, DOI: https://doi. org/10.1590/S1517-45222003000200004. Henry Bernstein, «Is There an Agrarian Question in the 21st Century?,» Canadian Journal of Development Studies/Revue Canadienne d'études Du Développement 27, $\mathrm{n}^{\circ} 4$ (2006): 449-460, DOI: https://doi. org/10.1080/02255189.2006.9669166; Shawn Van Ausdal, «Presentación del dossier "Nuevas historias agrarias de América Latina",» Historia Critica, n ${ }^{\circ} 51$ (2013): 13-19, DOI: https://doi.org/10.7440/histcrit51.2013.01.

40 La cuantificación estadística de campesinos/as es un ejercicio alquímico y terreno de batalla política. La controversia desatada en Colombia en 2016-17 a propósito de la inclusión del campesinado en las preguntas del Censo 2017 es paradigmática. Ver: ICANH, Elementos para la conceptualización de lo 'campesino' en Colombia: insumo para la inclusión del campesinado en el censo DANE 2017 (Bogotá: ICANH, febrero 2017), https://www.dejusticia.org/wp-content/uploads/2017/11/Conceptot\%C3\%A9cnico-del-Instituto-Colombiano-de-Antropolog\%C3\%ADa-e-HistoriaICANH.pdf.

41 William Roseberry, «Beyond the Agrarian Question in Latin America,» In Confronting Historical Paradigms. Peasants, Labor, and the Capitalist World System in Africa and Latin America, ed. Frederick Cooper, Florencia Mallon, Steve Stern, Allen Isaacman, y William Roseberry (Madison: The University of Wisconsin Press, 1993). 
estudios actuales conduce a pensar en una falta de renovación y ausencia de nuevas miradas, por lo que es necesario el ejercicio de la crítica ${ }^{42}$.

La inercia denunciada por Bengoa responde a un viraje de la atención de la historiografía latinoamericana de esos años hacia la historia cultural, la crítica posmoderna y hasta cierta medida la recepción y adaptación de los estudios subalternos y decoloniales, siguiéndole el hilo especialmente a la academia norteamericana. Los estudios agrarios con perspectivas históricas se reorientaban hacia la historia regional o local, y renunciaban patentemente a una visión macrohistórica, que había sido una verdadera pulsión mesiánica en las décadas anteriores, y por ello también su mayor limitación ${ }^{43}$. Durante los '90 -años de Consenso de Washington y recetas aperturistas, pero también de nuevas y más incluyentes cartas constitucionales y de resistencias indígenas y campesinas -la historia agraria se desteñía y revistas que fueron importantes del agrarismo social- como «Estudios Rurales Latinoamericanos» publicada por CLACSO en Bogotá desde 1978, cesaban publicaciones (1993).

Recientemente, sin embargo, la interpretación histórica de la cuestión agraria latinoamericana, después del ocaso de los Noventa, volvió a ser relevante en el tablero académico ${ }^{44}$.

42 Bengoa, «25 Años de Estudios Rurales...».

43 Aludo a los estudios que, influidos por las teorías de la modernización por un lado y por el estructuralismo y la teoría de la Dependencia por el otro lado, se interesaban a las experiencias históricas del campesinado latinoamericano desde distintos espectros ideológicos, pero en el común entendido de su necesaria desaparición futura, pues los campesinos en un caso representaban el eslabón del subdesarrollo a superar, y en el otro caso el grupo subyugado a emancipar. En ambos casos, se trataba de un distanciamiento notable de la interpretación originaria de Marx, Lenin y Kautsky, quienes tenían muy presente que el desarrollo capitalista producía formas de producción «híbridas» según las condiciones locales. La desaparición del campesinado no era postulada como una ley de la Historia. Akram-Lodhi y Kay, «Surveying the Agrarian Question,» 182,188.

44 En 2017 se inauguró en Chile el Centro de Estudios de Historia Agraria de América Latina, que en abril 2020 publicó el primer número de la Revista de Historia Agraria de América Latina. Claudio Robles-Ortiz, Cristóbal Kay, y Anna Cant, «Centro de Estudios de Historia Agraria de América Latina,» Centro de Estudios de Historia Agraria de América Latina (CEHAL), https://cehal.cl/centro/. Revista Historia Agraria de América Latina (HAAL), acceso el 3 de julio de 2020. https:// www.haal.cl/index.php/haal/about. 
Un rol significativo en esta resurrección lo jugó la historia ambiental, por razones que son metodológicas y conceptuales, como voy a argumentar a renglón seguido.

Los cambios historiográficos, al igual que los tecnológicos, ocurren cuando nuevos paradigmas conceptuales (el software) se juntan con herramientas metodológicas nuevas (el hardware). Ocurrió por ejemplo cuando el feminismo se volcó hacia la recuperación y producción de fuentes orales (que permitían superar la menor presencia de voces femeninas en la documentación textual tradicional), empezando a producir, primero, historias de mujeres y, luego, historias engendered, donde el género no era un complemento objeto de la proposición histórica, sino una clave de lectura de la historia. Ocurrió de nuevo con la historia económica, cuando el ocaso de las grandes metanarrativas del siglo XX y la disponibilidad de los computadores personales redireccionó el análisis históricoeconómico hacia la cliometría (y de paso alienó la historia económica de las demás corrientes de la disciplina).

De la misma forma, la "cuestión agraria» está siendo protagonista de un cambio historiográfico porque la perspectiva ambiental es un paradigma conceptual, que sacude las bases teóricas (economicistas) de esa cuestión, por un lado, y porque introduce herramientas metodológicas nuevas al laboratorio de su indagación, por otro.

Lo primero, la sacudida de la concepción economicista de la cuestión agraria ha sido propiciado por la agroecología, «aquella parte de la Ecología que (...) proporciona una visión integral de la estructura, funcionamiento y dinámica de los sistemas agrarios» ${ }^{45}$. Adoptada la visión agroecológica, ya no es posible seguir considerando un agroecosistema como «el objeto de una actividad económica llamada agricultura que "produce" alimentos, fibras, sustancias medicinales y combustibles y también beneficios monetarios", sino como el resultado siempre cambiante de las relaciones entre sus

45 Manuel González de Molina, "Agroecología e Historia Agraria. Una hibridación necesaria,» Estudios Rurales 1, n 1 (2011): 1-29, acceso el 3 de julio de 2020, https:// dialnet.unirioja.es/servlet/articulo?codigo $=4046044$. 
componente $^{46}$. Esto significa también repensar lo que los sistemas producen, a comenzar por la comida, desde el punto de vista energético y ambiental ${ }^{47}$.

Lo segundo, la introducción de herramientas metodológicas nuevas, está ocurriendo con la «reorientación desde conceptos muy conocidos - como paisajes, espacios y lugares-a unos menos conocidos -flujos, transformaciones en energía y metabolismos-y mucho menos tangibles que un árbol o un pájaro» ${ }^{48}$. Y estos vienen con sus propios instrumentos de medición, procedimientos y maneras de presentar resultados, es decir con su propia caja de herramientas.

En esta «nueva cuestión agraria», la pregunta clásica por la propiedad de la tierra deja de ser central ${ }^{49}$, y con ella los análisis de éxito o fracaso de las reformas agrarias a partir de las hectáreas de tierras redistribuidas, y los títulos de tierras como fuente principal de la historia agraria. Interesa en cambio saber si las transiciones agrarias, incluidas las que modificaron los marcos propietarios, alteraron significativamente la diversidad agrícola. «¿Cómo ha

46 González de Molina, «Agroecología e Historia Agraria,» 11.

47 De la transición de los estudios sobre comida y nutrición en sentido energético es elocuente representante Stefan Pohl, «"La Raza entra por la boca”: Energy, Diet and Eugenics in Colombia, 1890-1940,» HAHR 94, $\mathrm{n}^{\circ} 3$ (2014): 455-86.

48 John Soluri, «Tierras, montes y aguas: apuntes sobre energía, medio ambiente y justicia en las Américas,» Revista de Historia (Costa Rica), 59-60 (2009): 169-84, http://revistahistoria.historia.ucr.ac.cr/Numeros\%20Anteriores/ Vol.59:60/06tierrasmontesyagua.pdf. La referencia a flujos y transformaciones en energía alude al Metabolismo Socio-Ecológico. Ver Manuel González de Molina y Víctor Toledo, Metabolismos, naturaleza e historia. Hacia una teoría de las transformaciones socioecológicas (Barcelona: Icaria, 2011); Víctor M. Toledo, «Metabolismos rurales: hacia una teoría económico-ecológica de la apropiación de la naturaleza,» Revista Iberoamericana de Economía Ecológica, 7 (2008): 1-26. Enric Tello y Elena Galán del Castillo, «Sistemas agrarios sustentables y transiciones en el metabolismo agrario: desigualdad social, cambios institucionales y transformaciones del paisaje en Catalunya (1850-2010),» HALAC 2, $\mathrm{n}^{\circ} 2$ (30 august 2013): 267-306, acceso el 3 de julio de 2020, https://www.halacsolcha.org/index.php/halac/article/ view/294; Juan David Reina Rozo, «Metabolismo socioecológico como herramienta para la Historia Ambiental Urbana,» en Semillas de Historia Ambiental, ed. Stefania Gallini (Bogotá: Universidad Nacional de Colombia, 2015).

49 Para Palacios, escribiendo de Colombia, la pregunta por la propiedad de la tierra es el nudo gordiano de la historia del país. Marco Palacios, ¿¿De Quién Es La Tierra? Propiedad, Politización y Protesta Campesina en la Década de 1930 (Bogotá: FCE y Universidad de Los Andes, 2011). 
podido mantenerse (...) [la] diversidad agrícola a través de las numerosas revoluciones políticas, sociales, tecnocientíficas?», pregunta Soluri ${ }^{50}$.

Igualmente redefinida resulta otra pregunta canónica de la cuestión agraria latinoamericana: ¿cómo entender el lugar del agro y su gente en el marco de las transformaciones capitalistas de la tierra? Y aún más en concreto, ¿fueron las plantaciones el último refugio de la Colonia o la avanzada de la modernidad? Para Funes, las plantaciones caribeñas en el momento de la revolución de Haití en 1791 hay que verlas «en los marcos de la economía orgánica preindustrial, basada en la fuerza muscular humana y en los animales, junto a la fuerza motriz del viento y del agua», más que como unidades de producción de materias primas para la exportación, como acostumbra a conceptualizarlas la historia económica. La rebelión de esclavos en Haití -que abrió la era de las Revoluciones atlánticas-iba junto a «la rápida deforestación, la escasez de combustible, la erosión y la pérdida de fertilidad del suelo». No hay duda de que se trataba de desgracias ambientales, pero resulta que impulsaron sin embargo «la aplicación de innovaciones como los trenes de calderas a un solo fuego, capaces de quemar el residuo de la caña; empleo de estiércol para fertilizar las plantaciones; siembra de nuevas variedades de caña e implantación de regadíos». Y así, de la deforestación y el empobrecimiento del suelo y la afectación a la fauna, «las Antillas menores se convirtieron en territorios pioneros en la adopción de medidas conservacionistas, creación de jardines botánicos, reservas forestales y áreas protegidas ${ }^{51}$. La historia ambiental en su etapa de madurez logra por fin mostrarse rota y atormentada.

50 John Soluri, «Cocina casera: campesinos, cocina y diversidad agrícola,» en Un pasado vivo: dos siglos de historia ambiental latinoamericana, eds. Claudia Leal, John Soluri y José A. Padua, 179-99. (Bogotá: Fondo de cultura económica y Universidad de Los Andes, 2019), 183.

51 Reinaldo Funes Monzote, «El Gran Caribe en la metamorfosis de la tropicalidad,» en Un pasado vivo: dos siglos de historia ambiental latinoamericana, eds. Claudia Leal, John Soluri y José A. Padua (Bogotá: Fondo de cultura económica y Universidad de Los Andes, 2019), 60-61. 
Su nueva condición le permite atreverse a tocar las puertas de temas casi sagrados de las respectivas historiografías nacionales: la secuencia de revoluciones en México, que son repensadas como «revoluciones ecológicas» en las que lo que más cambia no es la política, sino las huellas sociales y ecológicas y su posibilidad de ejercer cambio a futuro $^{52}$; la "formación objetiva y subjetiva de Brazil como país», vista a partir del peso de una realidad territorial que pueblos y biomas fueron construyendo paulatinamente $\mathrm{y}$ juntos ${ }^{53}$; o la expansión incontrolada y destructora de la ganadería y su corolario de la consolidación de oligarquías agroexportadoras, una teorización que tuvo en escasa cuenta la extrema complejidad tanto de los ecosistemas como de las lógicas ganaderas ${ }^{54}$.

Por esta vía también asumen otro espesor las preguntas grandes de la historiografía latinoamericana, y dos en particular. La primera es, en palabras de Marixa Lasso, «The historical erasure of Latin American modernity» con la consecuente y cómoda consolidación de la idea de una América

52 Christopher R. Boyer y Martha Micheline Cariño Olvera, "Las revoluciones ecológicas de México,» en Un pasado vivo: dos siglos de historia ambiental latinoamericana, eds. Claudia Leal, John Soluri y José A. Padua (Bogotá: Fondo de cultura económica y Universidad de Los Andes, 2019); Christopher R. Boyer, ed., A Land Between Waters Environmental Histories of Modern Mexico (Tucson, Arizona: The University of Arizona Press, 2012); Mikael Wolfe, Watering the Revolution: An Environmental and Technological History of Agrarian Reform in Mexico (Durham: Duke University Press, 2017). La historiografía ambiental mexicana es, con Brasil, la que más ha sabido dialogar con su potente historiografía nacional. Entre las razones plausibles está su interés desde en comienzo por todas las temporalidades, incluida y quizá sobre todo la colonial. Ver Vera Candiani, Dreaming of Dry Land: Environmental Transformation in Colonial Mexico City (Stanford: Stanford University Press, 2014); Rosalva Loreto, ed., Agua, poder urbano y metabolismo social (Puebla: Benemérita Universidad Autónoma de Puebla, 2009); Miguel Aguilar Robledo, Humberto Reyes Hernández y Oscar Reyes Pérez, eds., La Historia ambiental en México: estudios de caso (San Luis Potosí: Universidad Autónoma de San Luis Potosí, 2019).

53 José Augusto Padua, «El dilema de la "cuna espléndida": naturaleza y territorio en la construcción de Brasil,» en Un pasado vivo: dos siglos de historia ambiental latinoamericana, eds. Claudia Leal, John Soluri y José A. Padua (Bogotá: Fondo de cultura económica y Universidad de Los Andes, 2019), 103-126.

54 Van Ausdal y Wilcox, «Un continente cubierto de pasto». Otras recientes historias ambientales ganaderas en Colombia que asumen miradas e investigan fuentes nuevas son Delgado Rozo, «Nuestras pobre vacas»; Katherinne Mora Pacheco, Entre sequías, heladas e inundaciones. Clima y sociedad en la Sabana de Bogotá, 1690-1870 (Bogotá: Universidad Nacional de Colombia, 2019). 
Latina que siempre estuvo en una carrera para alcanzar Europa y EEUU, «the idea of Latin America as a región of elite imitators and traditional peasants», evidentemente "a caricature that obscures the region's complex history ${ }^{55}$. El libro de Lasso, quien no se define a sí misma necesariamente como historiadora ambiental y que reconstruye con originalidad la contra-historia del Canal de Panamá y sus pobladores, es la prueba viva de que la perspectiva ambiental está siendo metabolizada por cualquiera que haga historia y tenga sensibilidad para los territorios, las otras especies no-humanas y la relación que la gente teje con ellos. La que queda borrada, nos narra Lasso, no es solo la serie de asentamientos que existían -y numerosos- en la Zona del Canal antes y después de su construcción, sino una manera de vivir -comerciando, transportándose, y cultivando- que pobladores locales habían negociado con la naturaleza tropical de la porción del istmo centroamericana ${ }^{56}$. Esa era también una «modernidad» latinoamericana.

\section{La construcción del Estado nacional y los pendientes metodológicos de la historia ambiental}

La segunda pregunta, o más bien idiosincrasia persistente de la historiografía latinoamericana, que una historia ambiental más madura puede contribuir a enriquecer, es la dinámica de construcción del Estado nacional (state and nation building). El problema del Estado -su formación, su fracaso, su dificultad para mantener el ejercicio de la soberanía,

55 Marixa Lasso, Erased: The Untold Story of the Panama Canal (Cambridge, MA: Harvard University Press, 2019), 12-13.

56 Lasso, Erased, 87. Como en otras situaciones latinoamericanas que la historia ambiental ha estudiado, expertos extranjeros de plantas, agriculturas, climas y otras especialidades resultaban burdos reconocedores de las prácticas locales, terminando por representar distintos territorios de la región como «vacíos» de actividad productiva, de personas y de conocimiento. Ver Stefania Gallini, Una Historia ambiental del café en Guatemala. La Costa Cuca entre 1830 y 1902 (Ciudad de Guatemala: AVANCSO, 2009); Nicolás Cuvi, «Improntas y remanentes indígenas en los Andes tropicales,» en Un pasado vivo: dos siglos de historia ambiental latinoamericana, eds. Claudia Leal, John Soluri y José A. Padua (Bogotá: Fondo de cultura económica y Universidad de Los Andes, 2019); John Soluri, Culturas bananeras: producción, consumo y transformaciones socioambientales (Bogotá: Universidad Nacional de Colombia y Siglos del Hombre, 2013). 
su peculiaridad en comparación a los caminos modélicos europeos o norteamericano, su captura por parte de algunas oligarquías, su persistencia no obstante las adversidades, la lentitud de su paso, su transformación en plurinacional- es quizá el problema-núcleo de la reflexión latinoamericana.

Frente a ello, la historiografía ambiental ofrece un camino innovador: la gestión de la naturaleza, o lo que un grupo de autores ha llamado Nature State, fue un gran laboratorio para experimentar soluciones administrativas, afinar capacidades de negociación, estrategias y alianza ${ }^{57}$. Así, los temas clásicos como el surgimiento de políticas de protección de áreas naturales o la historia de la gestión de parques se convierten en oportunidades para entender qué tipo de Estado se fue construyendo a partir de qué relación con una biodiversidad específica.

Siendo esta veta incipiente, es temprano para saber si encarna un potencial innovador importante para el estudio de la experiencia histórica del Estado en la región. Por lo pronto, se puede sin embargo observar que resulta curioso cómo la actuación del Estado siga estando en el centro del interés de una parte relevante de las ciencias sociales latinoamericanas, no obstante estas mismas hayan sostenido tradicionalmente la teoría de una atávica debilidad del Estado para ejercer sus funciones capitales. Si esto fuera cierto, ¿por qué no dedicarle atención a actores no-estatales (o de hecho contraestatales) que en varias etapas de la historia latinoamericana tuvieron control territorial y se consolidaron como institución con influencia para alterar la relación entre la sociedad y la naturaleza de lugares y zonas específicas. Por ejemplo, sería interesante comprender la forma en la que colonos y migrantes no organizados moldearon paisajes, o cómo las mafias narco interpretaron la naturaleza tropical, o cómo las guerrillas interactuaron con los animales del monte y de la selva, o cómo las transnacionales mineras intervieron en la litósfera? El pensamiento Estado-céntrico no contribuye

57 Wilko Graf von Hardenberg, Matthew Kelly, Claudia Leal, y Emily Wakild, eds., The Nature State: Rethinking the History of Conservation (London y New York: Routledge, 2017). 
a comprender estas otras formas, a veces antagónicas y no solo alternativas, de organizar la vida en comunidad. Quizá entonces un Nature-anti/alter State, a la par del Nature State ya mencionado, puede ser un planteamiento fecundo.

Con preguntas nuevas, como las anteriores, vienen metodologías y fuentes que pueden ayudar a renovar los métodos históricos más allá de la historia ambiental; sin embargo, a esta le sigue faltando claridad metodológica. ¿Cómo se hace historia ambiental? La respuesta es incierta porque no es común el interés hacia temas metodológicos entre historiadores ambientales, y porque los historiadores, a diferencia de los ingenieros de sistema, no cuentan con una tradición de documentación de sus pasos. Son pocas las referencias acerca del método para investigar y menos aún para enseñar historia ambiental desde y para América Latina, ni existen a la fecha (o no las pude encontrar) compilaciones como las de MacEachern y Turkel, para Canadá, y de Wakild y Berry ${ }^{58}$. El muy útil compendio editado por Myllyntaus no tiene en su mira a América Latina, pero los temas del uso de las biografías, la deconstrucción de las percepciones culturales del paisaje (incluido memoryscape), el diálogo con los saberes indígenas, el aprovechamiento historiográfico de los desastres como las inundaciones, y la oportunidad que representa la historia de los ríos para entender la relación sociedad-agua, son todos temas de mucha pertinencia para la historia ambiental de América Latina ${ }^{59}$.

58 Alan MacEachern y William J. Turkel, eds., Method and Meaning in Canadian Environmental History (Toronto: Nelson Education, 2009); Emily Wakild y Michelle K. Berry, A Primer for Teaching Environmental History: Ten Design Principles. (Durham y London: Duke University Press, 2018). Útil la experiencia de enseñanza de historia ambiental en paralelo entre un grupo en Viena (Austria) y otro en Río de Janeiro (Brasil) documentada por Rogério Ribeiro de Oliveira y Martin Schmid, «Bridging Continents in Teaching Environmental History: Rio de Janeiro and Vienna,» HALAC 1, $\mathrm{n}^{\circ} 1$ (30 september 2011): 74-85, acceso el 3 de julio de 2020, https://www.halacsolcha.org/index.php/halac/article/view/160. Stefania Gallini, «Problemas de métodos en la historia ambiental latinoamericana,» Anuario IHES, 19 (2004): 147-71 y Gallini, De la Rosa y Abello, «Historia Ambiental».

59 Timo Myllyntaus, ed., Thinking through the Environment: Green Approached to Global History (Cambridge: The White Horse Press, 2011), acceso el 3 de julio de 2020, http://www.environmentandsociety.org/sites/default/files/key_docs/myllyntaus.pdf. 
Un cierto número de autores latinoamericanos se ha encargado de traducir los postulados y los llamados 'genéricos' a la transdisciplinaridad, muy propia de la etapa inicial de la historiografía ambiental, a una serie de indicaciones metodológicas referidas a sus propios campos de investigación, por ejemplo, el todopoderoso Sistema de Información Geográfico, o los métodos para hacer historia climática para periodos preinstrumentales ${ }^{60}$.

Detrás de la adopción práctica (y no solo la postulación teórica) de la transdisciplinariedad están posiblemente varios elementos, de los que se destacan dos. El primero es la llegada de una generación de híbridos disciplinares, con estudios de pregrado en un área, de posgrado en otra y quizá de activismo en una tercera, resultado de una flexibilidad de los currículos universitarios latinoamericanos, tal vez mayor que la del norte del continente y de Europa ${ }^{61}$. El segundo elemento es la revolución digital, que, al permitir búsquedas de información por palabras claves en lenguaje natural (por ejemplo selva, en lugar de bosque húmedo tropical ${ }^{62}$ ), democratizó la ignorancia, que es notoriamente atrevida. Esto ha permitido a muchos dar pasos menos temblorosos en campos de saberes muy codificados. En tiempos pre-internet (que no son jurásicos, puesto que varios representantes de aquella época seguimos en circulación), cruzar en una misma investigación las últimas elucubraciones sobre los efectos a largo plazo de las reformas agrarias latinoamericanas en el siglo XX, con los hallazgos

60 Alexandro Solorzano, Rogério Ribeiro de Oliveira y Adi Lazos-Ruiz, «Landscape Reading Methodology of Urban Forests: Interpreting Past and Current Socioecological Interactions in Rio de Janeiro,» HALAC 6, $\mathrm{n}^{\circ} 1$ (9 septiembre 2016): 211-24, DOI: https://doi.org/10.5935/2237-2717.20160011; Rogério Ribeiro de Oliveira y Rita de Cássia Martins Montezuma, "História ambiental e ecologia da paisagem,» Mercator - Revista de Geografia da UFC 9, n 19 (2010): 117-28, acceso el 3 de julio de 2020, https://www.redalyc.org/articulo.oa?id=273620608010; Zephyr Frank, Eunice Sueli Nodari, and Celena Allen, From Forest to Vineyard: The Changing Landscape of Brazil (Stanford: Center for Spatial and Textual Analysis CESTA, 2017), acceso el 20 de abril de 2020, https://spatialhistory.wixsite.com/foreststovineyards; Katherinne Mora Pacheco, «Tras la pista de "terribles veranos" y "copiosas lluvias". Elementos para una historia climática del territorio colombiano,» Historia Crítica, $\mathrm{n}^{\circ} 74$ (2019): 19-40, DOI: https://doi.org/10.7440/histcrit74.2019.02.

61 Lo destacan con justo orgullo Sánchez-Calderón and Blanc, «La historia ambiental latinoamericana».

62 Agradezco una conversación con Claudia Leal por esta sugerencia. 
de la genética vegetal requería tiempo y valentía. Hoy día requiere tener conexión a internet.

\section{Conclusiones: el dilema Antropoceno}

La historiografía ambiental de América Latina ha producido en la última década más historias, pero sobre todo ha entrado en una etapa de madurez que le permite alejarse de narraciones teleológicas, y con ello encontrar un diálogo más proficuo con la Historia general. Por supuesto, sigue habiendo más temas pendientes que investigadores dispuestos a atenderlos. Algunas son faltas macroscópicas: los estudios de migración apenas han empezado a ser de interés para la historia ambiental ${ }^{63}$, mientras que en América Latina la historiografía ha sido más que tímida en cuanto a género y medio ambiente ${ }^{64}$. Entre los temas promisorios está el turismo, entendido como fenómeno transformador de gentes y de paisajes ${ }^{65}$. El listado podría seguir, pero no para hacer más completa la escena ${ }^{66}$, añadiendo roles y episodios, sino para hacer más compleja la

63 La mayor contribución viene del grupo liderado por Eunice Sueli Nodari en Brasil: Eunice Sueli Nodari y J. Klug, eds., História Ambiental e Migrações (Sao Leopoldo: Oikos, 2012); Eunice Sueli Nodari y Silvio Marcus de Souza Correa, eds., Migrações e Natureza (Sao Leopoldo: Oikos, 2013); Alanna Duarte, Mariluci Carelli y Roberta Meira, «Para plantar e colher arroz é preciso redesenhar a paisagem: narrativas de imigrantes europeus sobre o cultivo do arroz na colônia Dona Francisca (século XIX),» HALAC 9, $\mathrm{n}^{\circ} 2$ (13 diciembre 2019): 122-48, DOI: https://doi.org/10.32991/2237. 2717.2019v9i2.p122-148. Sobre el tema ver Marco Armiero y Richard Tucker, eds., Environmental History of Modern Migration (New York: Routledge, 2017).

64 Ofrece un mapeo conceptual Diana Ojeda, «Género, naturaleza y política: los estudios sobre género y medio ambiente,» HALAC 1, $\mathrm{n}^{0} 1$ (30 September 2011), https://www.halacsolcha.org/index.php/halac/article/view/159.

65 Claudia Martínez Herrera, "Protección de la naturaleza y turismo en la Revolución Cubana de 1959: el caso de la Ciénaga de Zapata,» HALAC 1, nº 2 (30 marzo 2012): 193-217, acceso el 3 de julio de 2020, https://www.halacsolcha.org/index. $\mathrm{php} /$ halac/article/view/152; Edgar Blanco Obando, «Turismo y metabolismo social: efectos ambientales de la actividad turística en la región Atlántico/Caribe. 19702011,» Diálogos. Revista Electrónica de Historia 17, no 1 (octubre 2016), acceso el 3 de julio de 2020, DOI: http://dx.doi.org/10.15517/dre.v17i1.17916; Funes Monzote, «El Gran Caribe en la metamorfosis de la tropicalidad», 73-76. Keely Maxwell, «Tourism, Environment, and Development on the Inca Trail,» Hispanic American Historical Review 92, n 1 (1 february 2012): 143-71. DOI: https://doi.org/10.1215/00182168 1470995. El tema se presta también para formatos comunicativos diversos. Ver por ej. el comic Riikka Laakso, "Airbus A300B and the Rise of Mass Tourism,» Environment \& Society Portal, Multimedia Library, 2014. http://www.environmentandsociety.org/ $\mathrm{mml} /$ airbus-a300b-and-rise-mass-tourism.

66 Leal, «Aguzar la mirada», 247. 
interpretación de la historia (y más difícil su manipulación). Cuando la historia ambiental lo logra, el diálogo con la historiografía general es fecundo.

Esta estrategia parte, sin embargo, del supuesto que la agenda de la investigación historiográfica ya existe, y la historia ambiental debería adaptarse a ella. Pero, si se acepta, como se comentaba en la Introducción, que el reto mayor de la historia ambiental es cambiar el sentido de la narración histórica, no adaptarse debería ser la consigna, y desafiar en cambio la historiografía en su propio terreno. ¿Podría el Antropoceno y su debate fungir como el caballo de Troya de la historia ambiental para penetrar la fortaleza de la historia, o será más bien un pantano en el cual se enterrará la perspectiva histórica, difuminada en las Humanidades ambientales y las demás prácticas culturales que están nutriendo lo que Astrid Ulloa llama «el giro antropocénico»? ${ }^{67}$.

El término Antropoceno nace en Cuernavaca, México, en febrero 2000. Lo lanza al agua pública Paul Crutzen, premio Nobel en Química 5 años antes, durante una reunión del International Geosphere-Biosphere Programme (IGBP) ${ }^{68}$. El concepto Antropoceno sale a la luz tres meses después, cuando Crutzen y su colega Stoermer formalizan por primera vez la propuesta de bautizar Antropoceno a la época geológica actual, caracterizada por el creciente y medible impacto de las actividades humanas sobre la Tierra y la atmósfera ${ }^{69}$, una acción humana tan gigantesca y duradera «que compite ahora con algunas de las más grandes fuerzas de la naturaleza en

67 Así lo tilda Astrid Ulloa, «Dinámicas ambientales y extractivas en el siglo XXI: ¿es la época del Antropoceno o del Capitaloceno en América Latina?,» Desacatos 54 (2017): 58-73, acceso el 3 de julio de 2020, http://desacatos.ciesas.edu.mx/index.php/ Desacatos/issue/view/102/showToc.

68 Nicola Davison, «The Anthropocene Epoch: Have We Entered a New Phase of Planetary History?,» The Guardian, 30 de Mayo de 2019, sección Environment, acceso el 3 de julio de 2020, https://www.theguardian.com/environment/2019/may/30/ anthropocene-epoch-have-we-entered-a-new-phase-of-planetary-history.

69 Crutzen y Stoermer, «The Anthropocene,» 17-18, diferencia entre término y concepto es relevante en el debate mismo del Antropoceno, y es una distinción que hace Chakrabarty, «Clima e historia. Cuatro tesis,» 51-69. 
su impacto sobre el funcionamiento del sistema Tierra ${ }^{70}$. Como recuerda Steffen ${ }^{71}$-otro protagonista de la historia del posicionamiento científico y político-presupuestal del Antropoceno-, Crutzen y su prestigio logran rápidamente que el nuevo concepto sea adoptado como «concepto-marco del significado último de cambio global», una transformación colosal cuya evidencia está en la alteración de los ciclos biogeofísicos del planeta, una población humana de un tamaño que el sistema-Tierra nunca había experimentado antes, un porcentaje de transformación de cobertura de la superficie terrestre también enorme, un número impresionante de especies extintas no por la caída de ningún meteorito, sino por la acción antrópica de sobrexplotación o transformación ecológica, la pérdida de enteros ecosistemas marinos, y otros indicadores más sobre los cuales florece la diatriba científica, mas no la generalizada aceptación de estar viviendo un cambio epocal $^{72}$.

El químico de la atmósfera Crutzen y el biólogo Stoermer avanzan igualmente en una propuesta de periodización histórica, de la nueva época geológica dominada por el ser humano: el Antropoceno comenzaría a finales del siglo XVIII, porque es a partir de esa fecha cuando los núcleos de los hielos glaciales delatan el comienzo del crecimiento de gases de efecto invernadero en la atmósfera. La causa es, continúan los dos científicos, la entrada en escena del motor a vapor en 1784 por el inocente James Watt, es decir el comienzo de la transición energética de la era moderna, dominada por la combustión fósil ${ }^{73}$.

El debate acerca del Antropoceno es interesante, entre otras razones, porque es prescriptivo. José Augusto Padua,

70 Will Steffen, Jacques Grinevald, Paul Crutzen, y John McNeill, «The Anthropocene: Conceptual and Historical Perspectives," Philosophical Transactions of the Royal Society A: Mathematical, Physical and Engineering Sciences 369, $\mathrm{n}^{\circ} 1938$ (13 March 2011): 842-67, DOI: https://doi.org/10.1098/rsta.2010.0327.

71 Steffen, «Commentary: Paul J. Crutzen and Eugene F. Stoermer, "The Anthropocene" (2000),» 486.

72 Steffen, Crutzen y McNeill, «The Anthropocene: Are Humans Now Overwhelming the Great Forces of Nature?,» 614-21.

73 Crutzen and Stoermer, «The Anthropocene», 18. 
quien escribe desde Río de Janeiro y no desde Estocolmo o Washington como otros autores antropocénicos, recuerda que algunos autores hablan de tres fases potenciales del Antropoceno: la primera, que iría desde la Revolución Industrial de finales del siglo XVIII; la segunda, llamada Gran Aceleración, desde el final de la Segunda Guerra Mundial; y la tercera, "a busca da sustentabilidade, ou seja, quando a humanidade, tomando consciência de que mudou de patamar, do risco que representa sua condição atual, possa buscar uma transição no rumo de um Antropoceno inteligentemente manejado» ${ }^{74}$.

Se va así consolidando un paradigma Antropoceno, que lee el pasado con miras a construir el futuro; varios autores latinoamericanos, en línea con algunos de los intelectuales más lúcidos de la academia crítica norteamericana, como Jason Moore y Donna Haraway, han contribuido a cuestionar no solo el término y la periodización del Antropoceno, sino la filosofía que está incrustada en la propuesta de la época dominada por los Humanos ${ }^{75}$. La misma revista HALAC le dio voz a esta scholarship dedicando un número (2019/1) al Capitaloceno, el término contrapropuesto por quienes reivindican lo erróneo que es atribuir a la especie humana la responsabilidad de haber transformado irremediablemente el planeta Tierra, cuando a toda luz es un porcentaje más bien

74 Amália Safatle, «Antropoceno 3.0. Entrevista a José Augusto Padua». Página 22, noviembre 2016, acceso el 27 de julio de 2020, https://pagina22.com.br/wp-content/ uploads/2016/10/P22-ED104a.pdf. Sobre la Gran Aceleración John R. McNeill y Peter Engelke, The Great Acceleration (Cambridge, MA: Harvard University Press, 2016).

75 Maristella Svampa y Francisco Longa, eds., «El Antropoceno como diagnóstico y paradigma. Lecturas desde América Latina,» Utopía y praxis latinoamericana $24, \mathrm{n}^{\circ} 88$ (2019), acceso el 3 de julio 2020, https://www.academia.edu/39162768/ El_Antropoceno_como_diagn\%C3\%B3stico_y_paradigma._Lecturas_desde_ Am\%C3\%A9rica_Latina; Virginia García Acosta, ed., "Cambio Climático y Antropoceno,» Desacatos, $\mathrm{n}^{\circ} 54$ (2017): 8-91, http://desacatos.ciesas.edu.mx/ index.php/Desacatos/issue/view/102/showToc.; Donna Haraway, "Antropoceno, capitaloceno, plantacionoceno, chthuluceno: generando relaciones de parentesco,» Revista Latinoamericana de Estudios Críticos Animales 3, $\mathrm{n}^{\circ} 1$ (2016): 15-26, acceso el 3 de julio 2020, https://revistaeca.files.wordpress.com/2016/07/1-haraway2.pdf; James W. Moore, ed., Anthropocene or Capitalocene? Nature, History, and the Crisis of Capitalism (Oakland, CA: Kairos PM Press, 2016), acceso el 3 de julio 2020, https:// www.academia.edu/24341220/Anthropocene_or_Capitalocene_Nature_History_and_ the_Crisis_of_Capitalism. 
localizado y reducido de seres humanos quienes, organizados en un modo de producción especialmente depredador de la naturaleza, como el Capitalismo, se ha encargado de producir aquellos cambios.

En este debate, que es en extremo relevante tanto desde el punto de vista especulativo -como ha demostrado Chakrabarty- como desde la perspectiva de la acción -como lo sostiene en particular la Antropología ambiental latinoamericana- «los historiadores en general han sido lentos en hacer propio el concepto de Antropoceno, pero cuando lo han hecho, han sido los historiadores ambientales que han guiado el camino» ${ }^{76}$.

Las razones para tenerle antipatía al "paradigma Antropoceno" son muchas y válidas ${ }^{77}$. Algunas que son relevantes para el oficio de historiador las recuerda McNeill: el Antropoceno estandariza la periodización de la historia mundial, porque la Estratigrafía -autoridad suprema en el nombramiento «oficial» de esta nueva época geológica-requiere leer la historia del mundo como un todo indiferenciado. Este es exactamente uno de los frentes de batalla más álgido en la investigación histórica, y especialmente en las propuestas decolonial. La Historia única no existe, aunque exista una dimensión global de la historia, en la que lugares distantes en el mundo se encuentran de repente conectados. Varias historias ambientales latinoamericanas recientes son escritas desde esta óptica: historias de arroz asiático en las tierras fértiles andinas, guano peruano en suelos británicos, epidemias migrantes, paquetes tecnológicos para la Revolución Verde diseñados en México, aplicados en Costa Rica, y transportados al otro lado del océano, y cobre chileno encendiendo farolas en las urbes de Europa. La historia global, sin embargo,

76 La afirmación es de McNeill y se refiere a Estados Unidos, pero bien es aplicable a América Latina también: John R. McNeill, «The Anthropocene and Environmental History in the USA,» HALAC 9, $\mathrm{n}^{\circ} 1$ (2019): 204, http://halacsolcha.org/index.php/ halac.

77 Marco Armiero expresa las suyas en Marco Armiero, «Sabotaging the Anthropocene: Or, in Praise of Mutiny,» en Future Remains, ed. Gregg Mitman, Marco Armiero, and Robert Emmett (Chicago y London: University of Chicago Press, 2018), 129-139. 
no equivale a universalizar la periodización histórica (por ejemplo, haciendo de la Revolución Industrial un único, monolítico acontecimiento con fecha de nacimiento en la casa de James Watt), una operación que los Estudios subalternos y decoloniales hace tiempo han desenmascarado.

La decisión sobre la "existencia» del Antropoceno, además, es jerárquica, burocrática y basada en una evidencia empírica específica, validada por un puñado de especialistas en una de las ramas de la Geología. Esto es evidentemente inconcebible para cualquier historiador en su sano juicio. De hecho, se podría decir que una buena dosis de los esfuerzos de quien se dedica profesionalmente a la Historia está en contradecir la "evidencia empírica». Sigue McNeill al respecto anotando que a los estatigrafistas no importa el porqué de lo que miden, sino la medición. En otras palabras, a historiadores y geólogos los separa la crítica de fuente, que para los geólogos debe ser una grosería, mientras para los historiadores es un artículo de fe.

Por último, la responsabilización unívoca del ser humano (que en realidad es el homo capitalistus) frente al cambio global, también resulta problemática en la medida en que la historia ambiental postula agencia histórica en la naturaleza no humana. El Antropoceno reafirmaría así el antropocentrismo que entorpece la comprensión de las relaciones cambiantes entre sistemas naturales y sistemas sociales.

Las objeciones al Antropoceno, como se aprecia, son serias y fundamentadas, y aún así, el paradigma avanza en su consolidación. Esta misma, me parece a mí, es la razón principal para interpretarlo como una oportunidad única para llevar las preocupaciones y la capacidad de análisis propias de la historia ambiental, al centro de la disciplina histórica.

\section{Bibliografía}

Aguilar Robledo, Miguel, Humberto Reyes Hernández, y Oscar Reyes Pérez, eds. La Historia ambiental en México: estudios 
de caso. San Luís Potosí: Universidad Autónoma de San Luís Potosí, 2019.

Akram-Lodhi, A. Haroon, y Cristóbal Kay. «Surveying the Agrarian Question (Part 1): Unearthing Foundations, Exploring Diversity." Journal of Peasant Studies 37, n 1 (2010): 177202. DOI: https://doi.org/10.1080/03066150903498838.

Andrade Franco, José, José Augusto Drummo, y Fernanda Pereira de Mesquita Nora. "History of Science and Conservation of the Jaguar (Panthera Onca) in Brazil.» HALAC 8, $\mathrm{n}^{\circ} 2$ (10 December 2018): 42-72. DOI: https://doi.org/10.32991/22372717.2018v8i2.p42-72.

Armiero, Marco. «Sabotaging the Anthropocene: Or, in Praise of Mutiny." En Future Remains, editado por Gregg Mitman, Marco Armiero, y Robert Emmett, 129-39. Chicago y London: University of Chicago Press, 2018.

Armiero, Marco y Richard Tucker, eds. Environmental History of Modern Migration. New York: Routledge, 2017.

Arruda, Gilmar, y Roger Colácios. «Considerações ético-políticas na História (ambiental): escalas e o presentismo da devastação.» HALAC 9, n 2 (2019): 64-94. DOI: https://doi. org/10.32991/2237-2717.2019v9i2.p64-94.

Barca, Stefania. "Uses of Environmental History.» Seeing the Woods (blog), 5 April 2017. Acceso el 25 de julio de 2020. https:// seeingthew oods.org/2017/04/05/uses-of-environmentalhistory-stefania-barca/.

Barles, Sabine. "History of Waste Management and the Social and Cultural Representations of Waste.» En The Basic Environmental History, editado por Mauro Agnoletti y Simone Neri Serneri, 199-226. Geneva: Springer, 2014.

Bauer, Jordan, y Martin V. Melosi. "Cities and the Environment.» En A Companion to Global Environmental History, editado por John R. McNeill y Erin S. Mauldin, 360-72. Hoboken, NJ: Wiley Blackwell, 2012. 
Bengoa, José. «25 Años de Estudios Rurales.» Sociologías 5, $\mathrm{n}^{\mathrm{o}} 10$ (2003): 36-98. DOI: https://doi.org/10.1590/S151745222003000200004 .

Bernstein, Henry. "Is There an Agrarian Question in the 21st Century?.» Canadian Journal of Development Studies/Revue Canadienne d'études Du Développement 27, nº 4 (2006): 449460. DOI: https://doi.org/10.1080/02255189.2006.9669166.

Bevilacqua, Piero. Demetra e Clio: Uomini e ambiente nella storia. Roma: Donzelli, 2001.

Blanco Obando, Edgar. «Turismo y Metabolismo Social: Efectos Ambientales de La Actividad Turística En La Región Atlántico/ Caribe. 1970-2011.» Diálogos. Revista Electrónica de Historia 17, $\mathrm{n}^{\circ} 1$ (octubre 2016). DOI: http://dx.doi.org/10.15517/dre. v17i1.17916.

Boyer, Christopher R., y Martha Micheline Cariño Olvera. «Las revoluciones ecológicas de México.» En Un pasado vivo: dos siglos de historia ambiental latinoamericana, editado por Claudia Leal, John Soluri y José A. Padua, 35-56. Bogotá: Fondo de Cultura Económica y Universidad de Los Andes, 2019.

«Latin American Environmental History.» En Oxford Research Encyclopedias: Latin American History, 1-24. Oxford: Oxford University Press, 2016. Edición en digital. Acceso el 20 de junio de 2020. https://www.academia. edu/28965338/Latin_American_Environmental_History.

ed. A Land Between Waters Environmental Histories of Modern Mexico. Tucson, Arizona: The University of Arizona Press, 2012.

Camus, Pablo, Sergio Castro, y Fabián Jaksic. «El conejo europeo en Chile: historia de una invasión biológica.» Historia 41, $\mathrm{n}^{\circ} 2$ (2008): 305-39. Acceso el 20 de junio de 2020. http:// revistahistoria.uc.cl/index.php/rhis/article/view/10696/9876

Candiani, Vera. Dreaming of Dry Land: Environmental Transformation in Colonial Mexico City. Stanford: Stanford University Press, 2014. 
Carey, Mark. "Latin American Environmental History: Current Trends, Interdisciplinary Insights, and Future Directions.» Environmental History, $n^{\circ} 14$ (2009): 221-52.

Cariño Olvera, Martha Micheline y Lorella Castorena, eds. Saberes para la sustentabilidad. Barcelona: Icaria, 2015.

Cariño Olvera, Martha Micheline, y Mario Monteforte. «An Environmental History of Nacre and Pearls: Fisheries, Cultivation and Commerce.» Global Environment 2, $\mathrm{n}^{\circ} 3$ (2009): 48-71. DOI: https://doi.org/10.3197/ge.2009.020303.

Cariño Olvera, Martha Micheline. «Origen, fortalecimiento y perspectivas de la Sociedad Latinoamericana y Caribeña de Historia Ambiental (SOLCHA).» HALAC 1, $\mathrm{n}^{\circ} 1$ (30 September 2011): 9-28. https://www.halacsolcha.org/index.php/halac/ article/view/157.

Castro Herrera, Guillermo. "América Latina: Historia Ambiental y Crisis Global.» En Por una historia ambiental latinoamericana: aportes para el estudio de la sociedad y la naturaleza en la era del Antropoceno, editado por Adrián Gustavo Zarrilli. Buenos Aires: Teseo, 2016.

Chakrabarty, Dipesh. "Clima e historia. Cuatro tesis.» Pasajes: Revista de pensamiento contemporáneo, $\mathrm{n}^{\circ} 31$ (2009): 51-69. Acceso el 20 de junio de 2020. https://dialnet.unirioja.es/ servlet/articulo? codigo $=3177488$.

Clare Rhoades, Patricia. «Un Balance de La Historia Ambiental Latinoamericana.» Revista de Historia, 59-60 (2009): 185201. Acceso el 3 de julio de 2020. https://www.revistas.una. ac.cr/index.php/historia/article/view/3474

Cronon, William. "The Uses of Environmental History.» Environmental History Review, 17 (1993): 1-22.

Crosby, Alfred W. The Columbian Exchange; Biological and Cultural Consequences of 1492. Westport, Conn.: Greenwood Pub. Co., 1972.

Imperialismo Ecológico. Barcelona: Crítica, 1988. 
Crutzen, Paul J., y E.F. Stoermer. "The Anthropocene.» IGBP Newsletter 41, $\mathrm{n}^{\circ} 12$ (2000): 17-18. Acceso el 3 de julio de 2020. http://www.igbp.net/ download/ 18.316f183213234701775800 01401/1376383088452/NL41.pdf.

Cuvi, Nicolás. «Improntas y remanentes indígenas en los Andes tropicales.» En Un pasado vivo: dos siglos de historia ambiental latinoamericana, editado por: Claudia Leal, John Soluri y José A. Padua, 80-102. Bogotá: Fondo de Cultura Económica y Universidad de Los Andes, 2019.

Delgado Rozo, Juan David. «"Nuestras pobre vacas de otros tiempos”: refinamiento ganadero y cambio de paisaje en La Sabana de Bogotá, 1860-1880.» En Semillas de Historia Ambiental, editado por Stefania Gallini, 183-214. Bogotá: Universidad Nacional de Colombia y Jardín Botánico de Bogotá, 2015.

Derby, Lauren. «Bringing the Animals Back in: Writing Quadrupeds into the Environmental History of Latin America and the Caribbean.» History Compass 9, $\mathrm{n}^{\circ} 8$ (2011): 602-21. Acceso el 12 de enero de 2020. https://www.academia.edu/5900624/ Bringing_the_Animals_Back_in_Writing_Quadrupeds_into_ the_Environmental_History_of_Latin_America_and_the_ Caribbean.

Duarte, Alanna, Mariluci Carelli, y Roberta Meira. «Para plantar e colher arroz é preciso redesenhar a paisagem: narrativas de imigrantes europeus sobre o cultivo do arroz na colônia Dona Francisca (século XIX).» HALAC 9, n ${ }^{\circ} 2$ (13 diciembre 2019): 122-48. DOI: https://doi.org/10.32991/2237-2717.2019v9i2. p122-148.

Dutra e Silva, Sandro, Marina Miraglia, y Wilson Picado. «Balances de Historia Ambiental en América Latina.» HALAC 9, $\mathrm{n}^{\circ} 2$ (19 diciembre 2019): 09-15. DOI: https://doi.org/10.32991/22372717.2019v9i2.p09-15.

De Carvalho Cabral, Diego, y otros, «Environmental History.» En Oxford Research Encyclopedia of Latin American History, Oxford: Oxford University Press, 2015-2020. Edición en digital. Acceso el 20 de junio de 2020. https://oxfordre.com/ latinamericanhistory/browse?btog=chap\&pageSize=20\&sort $=$ 
titlesort \&subSite= latinamericanhistory\&t0= ORE_LAH $\%$ 3AREFLAH020.

Eslava, Gabriela. Dejusticia blog. «Naturaleza: ¿víctima del conflicto?.» 8 de febrero de 2019. Acceso 20 de junio de 2020. https://www.dejusticia.org/naturaleza-victima-del-conflicto/.

Few, Martha, y Zeb Tortorici, eds. Centering Animals in Latin American History. Durham y London: Duke University Press, 2013. Añadir a pie de página

Frank, Zephyr, Eunice Sueli Nodari, y Celena Allen. «From Forest to Vineyard: The Changing Landscape of Brazil.» Center for Spatial and Textual Analysis CESTA, 2017. Acceso el 3 de julio de 2020. https://spatialhistory.wixsite.com/ foreststovineyards.

Funes Monzote, Reinaldo. «El Gran Caribe en la metamorfosis de la tropicalidad.» En Un pasado vivo: dos siglos de historia ambiental latinoamericana, editado por Claudia Leal, John Soluri y José A. Padua, 57-79. Bogotá: Fondo de Cultura Económica y Universidad de Los Andes, 2019.

«Facetas de la Interacción con los animales en Cuba durante el siglo XIX: los bueyes en la plantación esclavista y la Sociedad Protectora de Animales y Plantas.» Signos Históricos, no 16 (2006): 80-110. Acceso el 3 de julio de 2020. http://www.redalyc.org/resumen.oa?id=34401604.

Funes Monzote, Reinaldo, y Guillermo Castro Herrera. «La Historia Ambiental (hecha) en América Latina y el Caribe. Una actualización.» En Naturaleza en declive, Editado por Reinaldo Funes Monzote Valencia: Fundación Instituto de Historia Social, 2008.

Gallini, Stefania. «El Atila del Ganges en la ganadería colombiana.» Nómadas 22 (2005): 186-97. Acceso el 3 de julio de 2020. http:// nomadas.ucentral.edu.co/index.php/27-articulos-22/385-ElAtila-del-Ganges-en-la-ganader\%C3\%ADa-colombiana.

- «Historia, ambiente y política: el camino de la historia ambiental en América Latina.» Nómadas, 30 (2009): 92- 
102. Acceso el 20 de junio de 2020. https://www.redalyc.org/ pdf/1051/105112060008.pdf.

. «Invitación a La Historia Ambiental.» Tareas, 120 (2002):

5-27. Acceso el 20 de junio de 2020. https://www.redalyc.org/ pdf/5350/535055631002.pdf

- «Problemas de métodos en la Historia ambiental latinoamericana.» Anuario IHES (Argentina) 19 (2004): 14771.

. Una Historia ambiental del café en Guatemala. La Costa Cuca entre 1830 y 1902. Guatemala: AVANCSO, 2009.

Gallini, Stefania, Sofía De la Rosa y Rigoberto Abello. «Historia Ambiental.» En Hojas de ruta. Guías para el estudio socioecológico de la alta montaña en Colombia, editado por Paula Ungar. Bogotá: Instituto Alexander Von Humboldt, 2015. Edición en digital. Acceso el 3 de julio de 2020. http:// www.humboldt.org.co/es/component/k2/item/826-historiaambiental.

García Acosta, Virginia, ed. "Cambio Climático y Antropoceno.» Desacatos, $\mathrm{n}^{\circ} 54$ (2017): 8-91. http://desacatos.ciesas.edu.mx/ index.php/Desacatos/issue/view/102/showToc.

González de Molina, Manuel. «Agroecología e Historia agraria. Una hibridación necesaria.» Estudios Rurales 1, n 1 (2011): 1-29. Acceso el 3 de julio de 2020. https://dialnet.unirioja.es/servlet/ articulo? codigo $=4046044$.

González de Molina, Manuel, y Joan Martínez Alier. «Historia y Ecología: Introducción.» Ayer, n 11 (1993): 11-18.

González de Molina, Manuel, y Víctor Toledo. Metabolismos, naturaleza e historia. Hacia una teoría de las transformaciones socioecológicas. Barcelona: Icaria, 2011.

Graf von Hardenberg, Wilko, Matthew Kelly, Claudia Leal, y Emily Wakild, eds. The Nature State: Rethinking the History of Conservation. London and New York: Routledge, 2017. 
Haraway, Donna. "Antropoceno, Capitaloceno, Plantacionoceno, Chthuluceno: Generando Relaciones de Parentesco.» Revista Latinoamericana de Estudios Críticos Animales 3, $\mathrm{n}^{\mathrm{o}} 1$ (2016): 15-26. https://revistaeca. files.wordpress. com/ 2016/07/1-haraway2.pdf.

Hornborg, Alf, y Carole L. Crumley, eds. The World System and the Earth System: Global Socioenvironmental Change and Sustainability since the Neolithic. Walnut Creek, CA: Left Coast Press, 2007.

Horta Duarte, Regina. “"El zoológico del porvenir”: narrativas y memorias de nación sobre el Zoológico de Chapultepec, Ciudad de México, siglo XX.» Historia Crítica, $\mathrm{n}^{\circ} 72$ (3 abril 2019): 93-113. DOI: https://doi.org/10.7440/histcrit72.2019.05.

«História dos animais no Brasil: tradições culturais, historiografia e transformação.» HALAC $\quad 9, \mathrm{n}^{\circ} 2 \quad(13$ December 2019): 16-44. DOI: https://doi.org/10.32991/22372717.2019v9i2.p16-44.

«Narrativa, Historia Ambiental y Sustentabilidad.» En Saberes para la sustentabilidad, editado por Martha Micheline Cariño Olvera y Lorella Castorena, 195-206. Barcelona: Icaria, 2015.

Hunter, Richard. «Positionality, Perception, and Possibility in Mexico's Valle Del Mezquital.» Journal of Latin American Geography 8, $\mathrm{n}^{\mathrm{o}} 2$ (23 agosto 2009): 49-69. DOI: http://doi. org/10.1353/lag.0.0059.

ICANH. Elementos para la conceptualización de lo "campesino" en Colombia: insumo para la inclusión del campesinado en el censo DANE 2017. Bogotá: ICANH, Febrero 2017. https://www.dejusticia.org/wp-content/uploads/2017/11/ Concepto-t\%C3\%A9cnico-del-Instituto-Colombiano-deAntropolog\%C3\%ADa-e-Historia-ICANH.pdf.

Kautsky, Karl. La cuestión agraria. Madrid: Marxists Internet Archive [1903] 2015. Edición en digital. Acceso el 3 de julio de 2020. https://www.marxists.org/espanol/kautsky/1899/ kautsky-la-cuestion-agraria.pdf. 
Kay, Cristóbal. "Algunas reflexiones sobre los estudios rurales en América Latina." Íconos. Revista de Ciencias Sociales, 29 (2007): 31-50. Acceso el 3 de julio de 2020. http://www.flacso. org.ec/docs/i29kay.pdf.

Kheraj, Sean. «Nature's Past Episode 56: Animal Metropolis, Podcast, (29 Mayo 2017), MP3, 25:31.» NiCHE Network in Canadian Environmental History. Acceso el 9 de febrero de 2020. http://niche-canada.org/2017/05/29/natures-pastepisode-56-animal-metropolis/.

Kole de Peralta, Kathleen. «Mal Olor and Colonial Latin American History: Smellscapes in Lima, Peru, 1535-1614.» Hispanic American Historical Review 99, $\mathrm{n}^{\circ} 1$ (1 February 2019): 1-30. DOI: http://doi.org/10.1215/00182168-7287951.

Kreitman, Paul. «Attacked by Excrement: The Political Ecology of Shit in Wartime and Postwar Tokyo.» Environmental History 23, $\mathrm{n}^{\mathrm{o}} 2$ (1 abril 2018): 342-66. DOI: http://doi.org/10.1093/ envhis/emx136.

Laakso, Riikka. "Airbus A300B and the Rise of Mass Tourism.» Environment \& Society Portal, Multimedia Library, 2014. Acceso el 3 dejulio de 2020. http://www.environmentandsociety. org/mml/airbus-a300b-and-rise-mass-tourism.

Lasso, Marixa. Erased: The Untold Story of the Panama Canal. Cambridge, MA: Harvard University Press, 2019.

Latour, Bruno. Reensamblar lo social: una introducción a la teoría del actor-red. Buenos Aires: Manantial, 2008.

Leal, Claudia. "Aguzar la mirada colectiva, el gran desafío de la historia ambiental latinoamericana.» Historia y sociedad, 36 (2019): 243-68. DOI: https://doi.org/10.15446/hys.n36.71970.

Leal, Claudia, y otros. «Testimonios sobre la Tercera Escuela de Posgrados - SOLCHA.» SOLCHA, 2017. Acceso el 3 de julio de 2020. http://solcha.org/images/Testimonios_Goi\%C3\%A1s. pdf.

Leal, Claudia, John Soluri, y José Augusto Padua, eds. Un pasado vivo: dos siglos de historia ambiental latinoamericana. 
Bogotá: Fondo de cultura económica y Universidad de Los Andes, 2019.

López-López, Maximiliano. "Guerra de mieles: hipótesis para una historia ambiental de la miel de abeja en Costa Rica (19062014).» HALAC 8, no 2 (10 december 2018): 121-51. DOI: https://doi.org/10.32991/2237-2717.2018v8i2.

Loreto, Rosalva, ed. Agua, Poder Urbano y Metabolismo Social. Puebla: Benemérita Universidad Autónoma de Puebla, 2009.

Lossio, Jorge. Acequias y Gallinazos: Salud Ambiental En Lima Del Siglo XIX. Lima: IEP, Instituto de Estudios Peruanos, 2003.

MacEachern, Alan, y William J. Turkel, eds. Method and Meaning in Canadian Environmental History. Toronto: Nelson Education, 2009.

Martínez Herrera, Claudia. «Protección de la naturaleza y turismo en la Revolución Cubana de 1959: el caso de La Ciénaga de Zapata.» HALAC 1, no 2 (30 marzo 2012): 193-217. Acceso el 3 de julio de 2020. https://www.halacsolcha.org/index.php/ halac/article/view/152.

Mauch, Christof, ed. "Out of Sight, Out of Mind: The Politics and Culture of Waste.» RCC Perspectives: Transformations in Environment and Society, $\mathrm{n}^{\circ} 1$ (2016). DOI: https://doi. org/10.5282/rcc/7388.

Maxwell, Keely. «Tourism, Environment, and Development on the Inca Trail.» Hispanic American Historical Review 92, $\mathrm{n}^{\circ} 1$ (1 February 2012): 143-71. DOI: https://doi. org/10.1215/00182168-1470995.

McNeill, John R. Mosquito Empires: Ecology and War in the Greater Caribbean, 1620-1914. Cambridge: Cambridge University Press, 2010.

"The Historiography of Environmental History.» En The Oxford History of Historical Writing: Volume 5: Historical Writing Since 1945, editado por Axel Schneider and Daniel Woolf. Oxford: Oxford University Press, 2011. https://www. eolss.net/Sample-Chapters/C09/E6-156-01-00.pdf. 
. «The Uses of Environmental History.» Seeing the Woods (blog), 1 de marzo de 2017. Acceso 20 de junio de 2020. https:// seeingthewoods.org/2017/03/01/the-uses-of-environmentalhistory/.

. «The Anthropocene and Environmental History in the USA.» HALAC 9, $\mathrm{n}^{\circ} 1$ (2019): 200-210. http://halacsolcha.org/ index.php/halac.

McNeill, John R., y Peter Engelke. The Great Acceleration. Cambridge, MA: Harvard University Press, 2016.

Melville, Elinor G.K. Plaga de ovejas: consecuencias ambientales de la conquista de México. México, D.F.: Fondo de Cultura Económica, 1999.

Miller, Shawn W. «Latin America in Global Environmental History.» En A Companion to Global Environmental History, editado por John R. McNeill y Erin S. Mauldin, 116-31. Wiley Blackwell: Hoboken, NJ, 2012.

Miller, Shawn W. An Environmental History of Latin America. New York: Cambridge University Press, 2007.

Molano Camargo, Frank. «El relleno sanitario Doña Juana en Bogotá: la producción política de un paisaje tóxico, 1988-2019.» Historia Crítica, ${ }^{\circ} 74$ (2019): 127-49. DOI: http://https//doi. org/10.7440/histcrit74.2019.06.

Moon, David. «The Grasslands of North America and Russia.» En A Companion to Global Environmental History, editado por John R. McNeill and Erin S. Mauldin, 247-62. Wiley Blackwell: Hoboken, NJ, 2012.

Moore, James W., ed. Anthropocene or Capitalocene? Nature, History, and the Crisis of Capitalism. Oakland, CA: Kairos PM Press, 2016. https://www.academia.edu/24341220/ Anthropocene_or_Capitalocene_Nature_History_and_the_ Crisis_of_Capitalism.

Mora Pacheco, Katherinne. "Tras la pista de "terribles veranos" y "copiosas lluvias". Elementos para una historia climática del 
territorio colombiano.» Historia Crítica, n ${ }^{\circ} 74$ (2019): 19-40. DOI: https://doi.org/10.7440/histcrit74.2019.02.

Mora Pacheco, Katherinne. Entre sequías, heladas e inundaciones. Clima y sociedad en la Sabana de Bogotá, 1690-1870. Bogotá: Universidad Nacional de Colombia, 2019.

Müller, Simone M. "The Life of Waste.» Environment \& Society Portal, Virtual Exhibitions, $\mathrm{n}^{\circ} 3$ (2018), DOI: http://doi. org/10.5282/rcc/8452.

Myllyntaus, Timo, ed. Thinking through the Environment: Green Approached to Global History. Cambridge: The White Horse Press, 2011. http://www.environmentandsociety.org/sites/ default/files/key_docs/myllyntaus.pdf.

Ojeda, Diana. «Género, naturaleza y política: los estudios sobre género y medio ambiente.» $H A L A C 1, \mathrm{n}^{\circ} 1$ (30 septiembre 2011). Acceso el 3 de julio de 2020. https://www.halacsolcha. org/index.php/halac/article/view/159.

Oosthoek, Jan K. y Chris Pearson, «Canine City: Dogs and Humans in Urban History." Environmental History Resources, Podcast 47, 19 noviembre 2012, MP3. Acceso el 20 de junio de 2020. https://www.eh-resources.org/podcast-47/

Pedreros Troncoso, Pablo, Fernando Torrejón, Denisse Álvarez, y Roberto Urrutia. «Reconstruyendo la degradación ambiental del Lago Vichuquén, región del Maule, Chile, mediante el uso de registros históricos-documentales.» HALAC 9, $\mathrm{n}^{\circ} 1$ (18 June 2019): 149-77. DOI: https://doi.org/10.32991/22372717.2019v9i1.p149-177.

Padua, José Augusto. «Antropoceno 3.0». Página 22 (blog), 5 octubre 2016. Acceso el 20 de junio de 2020. http://pagina22.com. br/2016/10/05/antropoceno-3-0/.

. «El Dilema de la "cuna espléndida": naturaleza y territorio en la construcción de Brasil.» En Un pasado vivo: dos siglos de historia ambiental latinoamericana, editado por Claudia Leal, John Soluri y José A. Padua, 103-126. Bogotá: Fondo de cultura económica y Universidad de Los Andes, 2019. 
Palacio-Castañeda, Germán. "An Eco-Political Vision for an Environmental History: Toward a Latin American and North American Research Partnership.» Environmental History 17, $\mathrm{n}^{\circ} 4$ (1 otubre 2012): 725-43. DOI: https://doi.org/10.1093/ envhis/ems081.

Palacio-Castañeda, Germán. "Is There Any "Latin" in the Latin American Environmental History? New Challenges for the Consolidation of a Regional Intellectual Community.» HALAC 1, $\mathrm{n}^{\mathrm{o}} 2$ (2012): 157-79.

Palacios, Marco. ¿De quién es la tierra? Propiedad, politización y protesta campesina en la década de 1930. Bogotá: Fondo de Cultura Económica y Universidad de Los Andes, 2011.

Pintos, Graciela, Martha Micheline Cariño Olvera, y Raquel Briseño-Dueñas. "Relaciones históricas entre las tortugas marinas y las sociedades del finis terra bajacaliforniano.» HALAC 3, n ${ }^{\circ} 1$ (30 septiembre 2013): 89-115. Acceso el 3 de julio de 2020. https://www.halacsolcha.org/index.php/halac/ article/view/170.

Pohl, Stefan. «"La raza entra por la boca”: Energy, Diet and Eugenics in Colombia, 1890-1940.» HAHR 94, nº 3 (2014): 455-86.

Prudant, Elisabet. «Del caballo a la electricidad: imaginario ambiental y tecnológico en la transformación del sistema tranviario chileno a fines del siglo XIX.» Historia Crítica, $\mathrm{n}^{\circ} 74$ (2019): 41-64. DOI: https://doi.org/10.7440/histcrit74.2019.03.

Quintero Toro, Camilo. Birds of Empire, Birds of Nation. A History of Science, Economy, and Conservation in United StatesColombia Relations. Bogotá: Universidad de los Andes, 2012.

Reina Rozo, Juan David. «Metabolismo socioecológico como herramienta para la historia ambiental urbana.» En Semillas de Historia Ambiental, editado por Stefania Gallini, 75-124. Bogotá: Universidad Nacional de Colombia, 2015.

Ribeiro de Oliveira, Rogério, y Rita de Cássia Martins Montezuma. "História Ambiental e Ecologia da paisagem.» MercatorRevista de Geografia da UFC 9, nº 19 (2010): 117-28. Acceso 
el 3 de julio de 2020. https://www.redalyc.org/articulo. oa?id=273620608010.

Ribeiro de Oliveira, Rogério, y Martin Schmid. «Bridging Continents in Teaching Environmental History: Rio de Janeiro and Vienna." HALAC 1, $\mathrm{n}^{\circ} 1$ (30 September 2011): 74 -85. Acceso el 20 de junio de 2020. https://www.halacsolcha.org/index. $\mathrm{php/halac/article/view/160.}$

Rivera Castañeda, Patricia, y Refugio Chávez Ramírez, «La construcción de la historia ambiental en América.» Revista de El Colegio de San Luis 8, no 16 (2018): 171202. Acceso 12 de enero de 2020. https://www.redalyc.org/ jatsRepo/4262/426259450008/index.html.

Rodríguez Becerra, Manuel. «El ambientalismo en América Latina y el Caribe.» En Historia General de América Latina. Vol. VIII: América Latina desde 1930, ed. Marco Palacios, 551-76. París: UNESCO, 2008.

Roseberry, William. "Beyond the Agrarian Question in Latin America.» En Confronting Historical Paradigms. Peasants, Labor, and the Capitalist World System in Africa and Latin America, editado por Frederick Cooper, Florencia Mallon, Steve Stern, Allen Isaacman, y William Roseberry, 318-368. Madison: The University of Wisconsin Press, 1993.

Sánchez, R. «Animales en la ciudad: vecinos ocultos.» Ilé: Anuario de Ecología, Cultura y Sociedad 3, nº 3 (2003): 213-25.

Sánchez-Calderón, Vladimir, y Jacob Blanc. «La historia ambiental latinoamericana: cambios y permanencias de un campo en crecimiento.» Historia Crítica, n ${ }^{\circ} 74$ (2019): 3-18. DOI: https:// doi.org/10.7440/histcrit74.2019.01.

Santiago, Myrna. «EnvironmentalHistory.» En OxfordBibliographies Online: Latin American Studies. Oxford: Oxford University Press, 2013. Edición en digital. Acceso el 20 de junio de 2020. http://www.oxfordbibliographies.com/view/document/obo9780199766581/obo-9780199766581-0077.xml.

Sédrez, Lise F. «Latin American Environmental History: A Shifting Old/New Field.» En The Environment and World History, 
editado por E. Burke III and K. Pomeranz, 255-275. Berkeley and Los Angeles: The University of California Press, 2009.

. «nvironmental History of Modern Latin America.» En A Companion to Latin American History, editado por Thomas H. Holloway, 443-60. Malden, MA: Blackwell, 2008.

Sédrez, Lise F. y Regina Horta Duarte. «El muro y la hiedra: narrativas ambientales de un continente urbano.» En Un pasado vivo: dos siglos de historia ambiental latinoamericana, editado por Claudia Leal, John Soluri y José A. Padua, 15078. Bogotá: Fondo de Cultura Económica y Universidad de Los Andes, 2019.

Solíz Torres, María Fernanda. "Ecología política y geografía crítica de la basura en el Ecuador.» Letras Verdes. Revista Latinoamericana de Estudios Socioambientales, $\mathrm{n}^{\circ} 17$ (March 2015): 4-28.

Solórzano, Alexandro, Rogério Ribeiro de Oliveira, y Adi LazosRuiz. «Landscape Reading Methodology of Urban Forests: Interpreting Past and Current Socioecological Interactions in Rio de Janeiro.» HALAC 6, $\mathrm{n}^{\circ} 1$ (9 septiembre 2016): 211-24. DOI: https://doi.org/10.5935/2237-2717.20160011.

Soluri, John. "Cocina Casera: Campesinos, Cocina y Diversidad Agrícola'.» En Un pasado vivo: dos siglos de historia ambiental latinoamericana, editado por Claudia Leal, John Soluri y José A. Padua, 179-99. Bogotá: Fondo de cultura económica y Universidad de Los Andes, 2019.

Culturas bananeras: producción, consumo y transformaciones socioambientales. Bogotá: Universidad Nacional de Colombia y Siglos del Hombre, 2013.

. «History's Freaks of Nature.» Environmental History 10, $\mathrm{n}^{\circ} 1$ (2005): 94-95. https://www.jstor.org/stable/3985856

. «Tierras, montes y aguas: apuntes sobre energía, medio ambiente y justicia en las Américas.» Revista de Historia (Costa Rica), 59-60 (2009): 169-84. Acceso el 3 de julio de 2020. http://revistahistoria.historia.ucr.ac.cr/Numeros\%20 Anteriores/Vol.59:60/06tierrasmontesyagua.pdf. 
Sörlin, Sverker, y Paul Warde. «The Problem of the Problem of Environmental History: A Re-Reading of the Field.» Environmental History 12, n 1 (2007): 107-30. https://www. jstor.org/stable/25473035.

Steffen, Will. "Commentary: Paul J. Crutzen and Eugene F. Stoermer, "The Anthropocene" (2000)'.» En The Future of Nature, editado por Libby Robin, Sverker Sörlin, y Paul Warde, 486-90. New Haven: Yale University Press, 2013.

Steffen, Will, Paul J. Crutzen, y John R. McNeill. «The Anthropocene: Are Humans Now Overwhelming the Great Forces of Nature?.» Ambio 36, $\mathrm{n}^{\circ} 8$ (2007): 614-21. Acceso el 3 de julio de 2020. https://www.pik-potsdam.de/news/public-events/archiv/alternet/former-ss/2007/05-09.2007/steffen/literature/ambi-36-0806_614_621.pdf.

Steffen, Will, Jacques Grinevald, Paul Crutzen, y John McNeill. «The Anthropocene: Conceptual and Historical Perspectives.» Philosophical Transactions of the Royal Society A: Mathematical, Physical and Engineering Sciences 369, $\mathrm{n}^{\circ}$ 1938 (13 March 2011): 842-67. DOI: https://doi.org/10.1098/ rsta.2010.0327.

Strasser, Susan. Waste and Want: A Social History of Trash. New York: Henry Holt and Company, 2000.

Sueli Nodari, Eunice, y J. Klug, eds. História Ambiental e Migrações. Sao Leopoldo: Oikos, 2012.

Sueli Nodari, Eunice, y Silvio Marcus de Souza Correa, eds. Migrações e Natureza. Sao Leopoldo: Oikos, 2013.

Sutter, Paul. «The World with Us: The State of American Environmental History." Journal of American History 100, $\mathrm{n}^{\circ}$ 1 (2013): 94-119. DOI: https://doi.org/10.1093/jahist/jat095.

Svampa, Maristella y Francisco Longa, eds. «El Antropoceno como diagnóstico y paradigma. Lecturas desde América Latina.» Utopía y praxis latinoamericana 24, $\mathrm{n}^{\circ} 88$ (2019): sp. Acceso el 20 de junio de 2020. https://www.academia.edu/39162768/ El_Antropoceno_como_diagn\%C3\%B3stico_y_paradigma._ Lecturas_desde_Am\%C3\%A9rica_Latina. 
Tello, Enric, y Elena Galán del Castillo. «Sistemas agrarios sustentables y transiciones en el metabolismo agrario: desigualdad social, cambios institucionales y transformaciones del paisaje en Catalunya (1850-2010).» HALAC 2, $\mathrm{n}^{\circ} 2$ (30 August 2013): 267-306. Acceso el 20 de junio de 2020. https:// www.halacsolcha.org/index.php/halac/article/view/294.

Toledo, Víctor M. «Metabolismos rurales: hacia una teoría económicoecológica de la apropiación de la naturaleza.» Revista Iberoamericana de Economía Ecológica, 7 (2008): 1-26.

Tortolero Villaseñor, Alejandro. «The Annales School and the Environmental History of Latin America.» Historia Caribe 12, no 30 (June 2017): 301-40. DOI: https://doi.org/10.15648/ hc.30.2016.01.

Trujillo, Luis Ángel, Carlos Rodríguez, y Confucio Hernández. Piraiba: ecología ilustrada del gran bagre amazónico. Bogotá: Tropenbos, 2018.

Ulloa, Astrid. «Dinámicas ambientales y extractivas en el siglo XXI: ¿Es la época del Antropoceno o del Capitaloceno en América Latina?.» Desacatos 54 (2017): 58-73. Acceso el 3 de julio de 2020. http://desacatos.ciesas.edu.mx/index.php/Desacatos/ issue/view/102/showToc.

Van Ausdal, Shawn. «Potreros, ganancias y poder. Una historia ambiental de la ganadería en Colombia, 1850-1950.» Historia Crítica, 39E (2009): 126-49. Acceso el 3 de julio de 2020. DOI: https://doi.org/10.7440/histcrit39E.2009.07.

. «Presentación del dossier 'Nuevas historias agrarias de América Latina'.» Historia Crítica, n 51 (2013): 13-19. DOI: https://doi.org/10.7440/histcrit51.2013.01.

Van Ausdal, Shawn y Robert W. Wilcox. «Un continente cubierto de pasto: ganadería y transformación del paisaje.» En Un pasado vivo: dos siglos de historia ambiental latinoamericana, editado por Claudia Leal, John Soluri y José A. Padua, 20022. Bogotá: Fondo de Cultura Económica y Universidad de Los Andes, 2019. 
Vergara, Germán. "Animals in Latin American History.» En Oxford Research Encyclopedia of Latin American History: Environmental History. Oxford: Oxford University Press, 2018. DOI:https://doi.org/10.1093/acrefore/9780199366439.013.436.

Wakild, Emily, y Michelle K. Berry. A Primer for Teaching Environmental History: Ten Design Principles. Durham y London: Duke University Press, 2018.

Wewers, Dan. A Brief Guide to Writing the History Paper. Cambridge, MA.: Harvard College Writing Center, 2007. Edición en digital. Acceso el 20 de junio de 2020. https://hwpi.harvard. edu/files/hwp/files/bg_writing_history.pdf.

Wolfe, Mikael. Watering the Revolution: An Environmental and Technological History of Agrarian Reform in Mexico. Durham: Duke University Press, 2017.

Zarrilli, Adrián Gustavo. «Nuevas formas de politización y conflictos socio-ambientales en el mundo rural argentino: las provincias de Chaco y Formosa frente a los procesos de deforestación y avance de la frontera agrícola (1980-2010).» HALAC 6, $\mathrm{n}^{\circ} 1$ (9 septiembre 2016): 11-29. DOI: https://doi.org/10.5935/22372717.20160002 .

\section{Sitios web}

Bibliografía Zotero. "BOHA - Bibliografía Online de Historia Ambiental Latinoamericana.» Acceso el 20 abril 2015. https:// www.zotero.org/groups/solcha-boha/items/order/title/sort/asc.

Centro de Estudios de Historia Agraria de América Latina (CEHAL). Revista Historia Agraria de América Latina (HAAL), 2017. Acceso el 3 de julio de 2020. https://www.haal.cl/index.php/ haal/about.

Centro de Estudios de Historia Agraria de América Latina (CEHAL). «Centro de Estudios de Historia Agraria de América Latina.» https://cehal.cl/centro/.

Corporation for Digital Scholarship. Zotero. 2006. Acceso el 20 de junio de 2020. https://www.zotero.org/. 
Discard Studies. Acceso 20 de junio de 2020. https://discardstudies. com/.

Elsevier. "Scopus.» Acceso el 30 de enero de 2020. https://www. scopus.com/home.uri?zone=header\&origin $=$.

Environment \& Society Portal.» Rachel Carson Center for Environment and Society. "Acceso el 5 febrero de 2020. http:// www.environmentandsociety.org/.

Fundación Dialnet. «Dialnet.» Acceso el 30 de enero de 2020. https:// dialnet.unirioja.es.

HackCurio (blog). «Gabriella 'Biella' Coleman, E., HackCurio: Decoding the Cultures of Hacking.» Acceso 6 de febrero de 2020. https://hackcur.io/.

Paper Machines, visualize thousands of texts with the click of a button, 2012. Acceso el 3 de julio de 2020. http://papermachines.org/.

Sinclair, Stéfan y Geoffrey Rockwell. Voyant Tools. Acceso el 8 de febrero de 2020. https://voyant-tools.org/.

The Programming Historian. «Análisis de corpus con Voyant Tools de Silvia Gutiérrez.» Acceso el 20 de junio de 2020. https:// programminghistorian.org/es/lecciones/analisis-voyant-tools.

Universidad Autónoma del Estado de México. Redalyc - Red de Revistas Científicas de América Latina y El Caribe, España y Portugal. Acceso el 30 de enero de 2020. https://www.redalyc. org/.

YouTube. «VI SOLCHA - Regina Horta Duarte: Zoo geografía del Brasil.» Acceso el 20 de junio de 2020. https://www. youtube.com /watch?v= PYzDYmSkCPY \&list= PL4D3334F4 $\mathrm{C} 8 \mathrm{C} 2 \mathrm{E} 604$ \&index $=4$.

\section{Periódico}

Davison, Nicola. «The Anthropocene Epoch: Have We Entered a New Phase of Planetary History?». The Guardian, 30 de mayo de 2019. Acceso el 3 de julio de 2020. https://www.theguardian. 
com/environment/2019/may/30/anthropocene-epoch-have-weentered-a-new-phase-of-planetary-history.

Safatle, Amália. «Antropoceno 3.0. Entrevista a José Augusto Padua». Página 22, noviembre 2016. Acceso el 27 de julio de 2020. https://pagina22.com.br/wp-content/uploads/2016/10/ P22-ED104a.pdf

\section{Citar este artículo}

Gallini, Stefania. "¿Qué hay de Histórico en la Historiografía ambiental en América Latina?.» Historia Y MEMORIA, $\mathrm{n}^{\circ}$ Especial (2020): 179-233. DOI: https:/doi. org/10.19053/20275137.nespecial.2020.11586. 